\title{
The Crystal Structures and Powder \\ Diffraction Patterns of the Uranium
}

\section{Tellurides: A Critical Review}

\author{
Robert L. Snyder \\ Instifute for Ceramic Superconductivity \\ New York State \\ College, Ceramics at Alfred University \\ Alfred, NY 14802 \\ and \\ Monte C. Nichols and Dale R. Boehme \\ Sandia National Laboratories \\ Livermore CA 94551
}

October 3, 1990 


\section{Contents}

1 Introduction $\quad 13$

2. Reported Phases in the U-Te System 14

$\begin{array}{lll}3 \text { UTe } & 20\end{array}$

$4 \mathrm{U}_{3} \mathrm{Te}_{4}\left(\mathrm{UTe}_{1.333}\right) \quad 22$

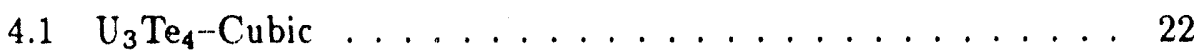

$4.2 \mathrm{U}_{3} \mathrm{Te}_{4}$-Orthorhombic . ............... 26

$\begin{array}{lll}5 & \mathrm{U}_{2} \mathrm{Te}_{3}\left(\mathrm{UTe}_{1.5}\right) & \mathbf{2 7}\end{array}$

$5.1 \mathrm{U}_{2} \mathrm{Te}_{3}$-Cubic ....................... 27

$5.2 \mathrm{U}_{2} \mathrm{Te}_{3}$-Orthorhombic . . . . . . . . . . . . 32

$6 \mathrm{U}_{3} \mathrm{Te}_{5}\left(\mathrm{UTe}_{1.666}\right)$

$7 \mathrm{U}_{7} \mathrm{Te}_{12}\left(\mathrm{UTe}_{1.714}\right)$

$\begin{array}{llll}8 & \mathrm{UTe}_{1.78} & 47\end{array}$

$8.1 \mathrm{UTe}_{1.78}$-Orthorhombic . . . . . . . . . . 47

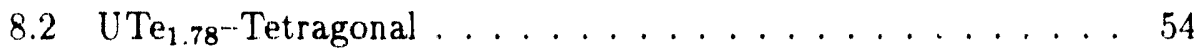

$\theta \mathrm{UTe}_{2} \quad 54$

$9.1 \mathrm{UTe}_{2}$-Orthorhombic .................... 54

$9.2 \mathrm{UTe}_{2}$-Tetragonal ................... 63

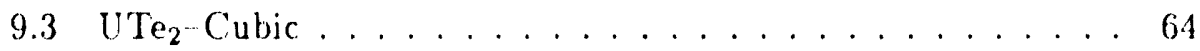




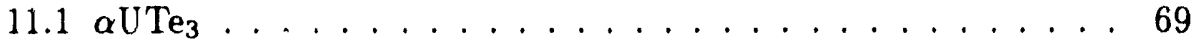

$11.2 \beta \mathrm{UTe}_{3}$ and $\mathrm{UTe}_{3.4} \ldots \ldots \ldots \ldots \ldots$

$12 \mathrm{UTe}_{5}$

\section{List of Figures}

1 Phase diagram for the tellurium uranium system. . . . . . 14

\section{List of Tables}

1 Space group and unit cells for the U-Te phases. . . . . . 16

2 Physical constants for the U-Te phases. . . . . . . . 17

3 A tom locations and site occupancy. . . . . . . . . . . 18

3 (continued). Atom locations and site occupancy. . . . . . 19

4 Calculated (left) and the NBS calculated (right) PDF pattern $(15-856)$ for UTe. . . . . . . . . . . . . . 21

5 Calculated (left) and the observed (12-610) powder pattern for cubic $\mathrm{U}_{3} \mathrm{Te}_{4}, \ldots \ldots \ldots \ldots \ldots$

5 (continued). Calculated (left) and the observed (12-610) powder pattern for cubic $\mathrm{U}_{3} \mathrm{Te}_{4} \ldots \ldots \ldots \ldots 24$ 
5 (continued). Calculated (left) and the observed (12-610) powder pattern for cubic $\mathrm{U}_{3} \mathrm{Te}_{4} \ldots \ldots \ldots \ldots$

6 Calculated pattern for cubic $\mathrm{U}_{2} \mathrm{Te}_{3}$ (left) and the observed (12-610) pattern for $\mathrm{U}_{3} \mathrm{Te}_{4} \ldots \ldots \ldots \ldots \ldots$

6 (continued). Calculated pattern for cubic $\mathrm{U}_{2} \mathrm{Te}_{3}$ (left) and the observed $(12-610)$ pattern for $\mathrm{U}_{3} \mathrm{Te}_{4} \ldots \ldots \ldots$

6 (continued). Calculated pattern for cubic $\mathrm{U}_{2} \mathrm{Te}_{3}$ (left) and the observed (12-610) pattern for $\mathrm{U}_{3} \mathrm{Te}_{4} \ldots \ldots \ldots 31$

7 Lattice parameters for the orthorhombic $\mathrm{U}_{2} \mathrm{Te}_{3}-\mathrm{U}_{3} \mathrm{Te}_{4}$ solid solution range. $\ldots \ldots \ldots \ldots \ldots \ldots$

8 Calculated and PDF patterns (34-807 and 21-1408) for $\mathrm{U}_{2} \mathrm{Te}_{3} .35$

8 (continued). Calculat 1 and PDF patterns (34-807 and 211408) for $\mathrm{U}_{2} \mathrm{Te}_{3}, \ldots \ldots \ldots \ldots \ldots \ldots$

8 (continued). Calculated and PDF patterns (34-807 and 21. 1408) for $\mathrm{U}_{2} \mathrm{Te}_{3} \ldots \ldots \ldots \ldots \ldots \ldots \ldots \ldots$

8 (continued). Calculated and PDF patterns (34-807 and 211408) for $\mathrm{U}_{2} \mathrm{Te}_{3} . \ldots \ldots \ldots \ldots \ldots \ldots$

8 (continued). Calculated and PDF patterns (34-807 and 211408) for $\mathrm{U}_{2} \mathrm{Te}_{3}, \ldots \ldots \ldots \ldots \ldots$

8 (continued). Calculated and PDF patterns (34-807 and 211408) for $\mathrm{U}_{2} \mathrm{Te}_{2} \ldots \ldots \ldots \ldots \ldots \ldots$

9 Lattice parameters for the reported orthorhombic forms of $\mathrm{U}_{3} \mathrm{Te}_{5} \ldots \ldots \ldots \ldots \ldots \ldots \ldots \ldots \ldots$ 
10 Calculated and PDF patterns (24-1368 and 21-1407) for $\mathrm{V}_{7} \mathrm{Te}_{1 \%} .43$

10 (continued). Calculated and PDF patterns (24-1368 and 211407) for $\mathrm{U}_{7} \mathrm{Te}_{12} \ldots \ldots \ldots \ldots \ldots \ldots$. . . . . . . . . 44

10 (continued). Calculated and PDF patterns (24-1368 and 211407) for $\mathrm{U}_{7} \mathrm{Te}_{12} \ldots \ldots \ldots \ldots \ldots \ldots \ldots$

10 (continued). Calrulated and PDF patterns (24-1368 and 211407) for $\mathrm{U}_{7} \mathrm{Te}_{12} \ldots \ldots \ldots \ldots \ldots \ldots \ldots$

11 Calculated pattern for $\mathrm{UTe}_{1.78}$ (left) and the observed (211404) for the claimed $\mathrm{U}_{4} \mathrm{Te}_{7} \ldots \ldots \ldots \ldots \ldots$

11 (continued). Calculated pattern for $\mathrm{UTe}_{1.78}$ (left) and the observed (21-1404) for the claimed $\mathrm{U}_{4} \mathrm{Te}_{7} \ldots \ldots \ldots$. . . . 49

11 (continued). Calculated pattern for $\mathrm{UTe}_{1.78}$ (left) and the observed (21-1404) for the claimed $\mathrm{U}_{4} \mathrm{Te}_{7} \ldots \ldots \ldots$. . . . 50

11 (continued). Calculated pattern for $\mathrm{UTe}_{1.78}$ (left) and the observed $(21-1404)$ for the claimed $\mathrm{U}_{4} \mathrm{Te}_{7} \ldots \ldots \ldots$

11 (continued). Calculated pattern for $\mathrm{U}^{\prime} \mathrm{e}_{1.78}$ (left) and the observed (21-1404) for the claimed $\mathrm{U}_{4} \mathrm{Te}_{7} \ldots \ldots \ldots 52$

11 (continued). Calculated pattern for $\mathrm{UTP}_{1.78}$ (left) and the observed (21-1404) for the claimed $\mathrm{U}_{4} \mathrm{Te}_{7} \ldots \ldots \ldots 53$

12 Calculated and observed patterns (Boehme et al. and 241370) for orthorhombic $\mathrm{UTe}_{2} \ldots \ldots \ldots \ldots$

12 (continued). Calculated and observed patterns (Boehme et al. and 24-1370) for orthorhombic UTe $\ldots \ldots \ldots$ 
12 (continued). Calculated and observed patterns (Boehme et al. and 24-1370) for orthorhombic $\mathrm{UTe}_{2} \ldots \ldots \ldots$

12 (continued). Calculated and observed patterns (Boehme et al. and 24-1370) for orthorhombic UTe $\ldots \ldots \ldots$

12 (continued). Calculated and observed patterns (Boehme et al. and 24-1370) for orthorhombic UTe $\mathrm{UT}_{2} \ldots \ldots \ldots$

12 (continued). Calculated and observed patterns (Boehme et al. and 24-1370) for orthorhombic UTe $\ldots \ldots \ldots 6$

12 (continued). Calculated and observed patterns (Boehme et a. and 24-1370) for orthorhombic UTe $\ldots \ldots$. . . . . 62

13 Calculated pattern for the postulated pyrite structured $\mathrm{UTe}_{2}$ (left) and the reported (35-1483) pattern. . . . . . . . 66

14 Boehme et al. and Grønvold et al. patterns for $\mathrm{UTe}_{2.5} \ldots \ldots 68$

15 Calculated pattern for $\alpha \mathrm{UTe}_{3}$ (left) and the observed (27-929 and $21-1403) \ldots \ldots \ldots \ldots \ldots$

15 (continued). Calculated pattern for $\alpha \mathrm{UTe}_{3}$ (left) and the observed $(27-929$ and $21-1403) . \ldots \ldots \ldots 71$

15 (continued). Calculated pattern for $\alpha \mathrm{UTe}_{3}$ (left) and the observed (27-929 and 21-1403). . . . . . . . . . . 72

15 (continued). Calculated pattern for $\alpha \mathrm{UTe}_{3}$ (left) and the ob-

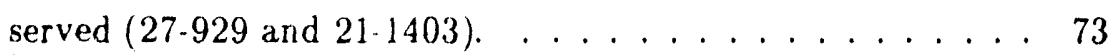

15 (continued). Calculated pattern for $\alpha \mathrm{UTe}_{3}$ (left) and the observed (27-929 and 21-1403). . . . . . . . . . 74 
16 Observed patterns for $\mathrm{UTe}_{3.4}$ Boehme et al. and $\mathrm{UTe}_{3.38}$ (24$1369)$, and the calculated pattern for $\beta \mathrm{UTe}_{3} \ldots \ldots \ldots 77$

16 (Continued). Observed patterns for $\mathrm{UTe}_{3.4}$ Boehme et al. and $\mathrm{UTe}_{3.38}$ (24-1369), and the calculated pattern for $\beta \mathrm{U}^{\prime} \mathrm{Te}_{3} . \quad 78$

17 Calculated pattern for $\mathrm{UTe}_{5}$ (left) and observed, 36-1291 (middle), Boehme et al. (right). . . . . . . . . . . . . 80

17 (continued). Calculated pattern for $\mathrm{UTe}_{5}$ (left) and observed, 36-1291 (middle), Boehme et al. (right). . . . . . . . . . 81

17 (continued). Calculated pattern for $\mathrm{UTe}_{5}$ (left) and observed, 36-1291 (middle), Boehme et al. (right) . . . . . . . . . 82

17 (continued). Calculated pattern for $\mathrm{UTe}_{5}$ (left) and observed, 36-1291 (middle), Boehme et al. (right). . . . . . . . . . 83

17 (continued). Calculated pattern for $\mathrm{UTe}_{5}$ (left) and observed, 36-1291 (middle), Boehme et al. (right). . . . . . . . . 84

17 (continued). Calculated pattern for $\mathrm{UTe}_{5}$ (left) and observed, 36-1291 (middle), Boehme et al. (right). . . . . . . 85 


\begin{abstract}
A critical review of all of the reported structures and powder diffraction patterns in the urinium telluride system has been undertaken.

1. Structures that are correct:

- Cubic - UTe: no experimental pattern exists. Retain calculated 15-865.

- Cubic $-\mathrm{U}_{3} \mathrm{Te}_{4}$ : retain the poor quality $12-610$ but adopt the pattern calculated here.

- Cubic $\mathrm{U}_{2} \mathrm{Te}_{3}$ : no experimental pattern exists. Adopt pattern calculated here.

- Orthorhombic UTe 2 : Adopt the new pattern of Boehme et al.

- Monoclinic $\alpha \mathrm{UTe}_{3}$ Adopt the new pattern of Boehme et al.

- Orthorhombic $\beta \mathrm{UTe}_{3}$ : Adopt pattern calculated here.

- Orthorhombic UTes: Adopt the $n^{\wedge} w$ pattern of Boehme et al.
\end{abstract}

2. Structures in need of refinement:

- Orthorhombic $\mathrm{U}_{2} \mathrm{~T}_{3}$ : Adopi pattern calculated here over 34-807.

- Hexagonal $\mathrm{U}_{7} \mathrm{Te}_{12}$ : Adopt pattern calculated here but retain 241368. 
- Orthorhombic UTe ${ }_{1.78}$ : Adopt, pattern calculated here and retain our modified 21-1404 reported for $\mathrm{U}_{4} \mathrm{Te}_{7}$.

- Orthorhombic UTe 2.5 : Adopt pattern calculated here.

- Orthorhombic UTe $\mathrm{UT}_{3.4}$ : Accept recent pattern of Boehme et al.

3. Phases for which no structures or reliable patterns exist:

- Orthorhombic $\mathrm{U}_{3} \mathrm{Te}_{4}$ : no published pattern.

- Tetragonal $\mathrm{U}_{3} \mathrm{Te}_{5}$ : three patterns $21-1407,34-766$ and 34-896 exit but all are of very poor quality.

4. Phases which probably do not exist:

- Tetragonal UTe 1.78

- Tetragonal UTe

- Cubic $\mathrm{UTe}_{2}$

- $\mathrm{U}_{3} \mathrm{Te}_{7}(21-1402)$

- $\mathrm{U}_{3} \mathrm{Te}_{8}(21-1406)$ 


\section{Introduction}

The many allowed oxidation states of the actinide metals make the phase diagrams of their Chalcogenide compounds among the most complex known. Researchers have long been plagued with what appeared to be mixtures

of an endless series of phases in these systems. Many of the phases have been poorly characterized using powder diffraction patterns which were either nonexistent, incorrect or incomplete. To assess this problem, we have undertaken a critical review of all of the reported structures and powder diffraction patterns in the most complicated of the systems, the uranium tellurides. The phase diagram for this system continues to change with the newest phase reported as recently as 1989[22]. Figure 1 shows the currently understood phase diagram[9] as updated by this study and illustrates ine numker of phases which have been described. An extremely valuable structural survey of this system is contained in the thermodynamic summary of F. Grønvold, J. Drowart and E. F. Westrum[13]. We will not repeat all of the references given there, but will concentrate on those most pertinent to our goal of establishing a set of consistent powder diffraction standards and confirming the various proposed structural models.

The paper will be divided into sections treating every reported phase in the U-Te system, including reports which we cunclude to be erroneous. 


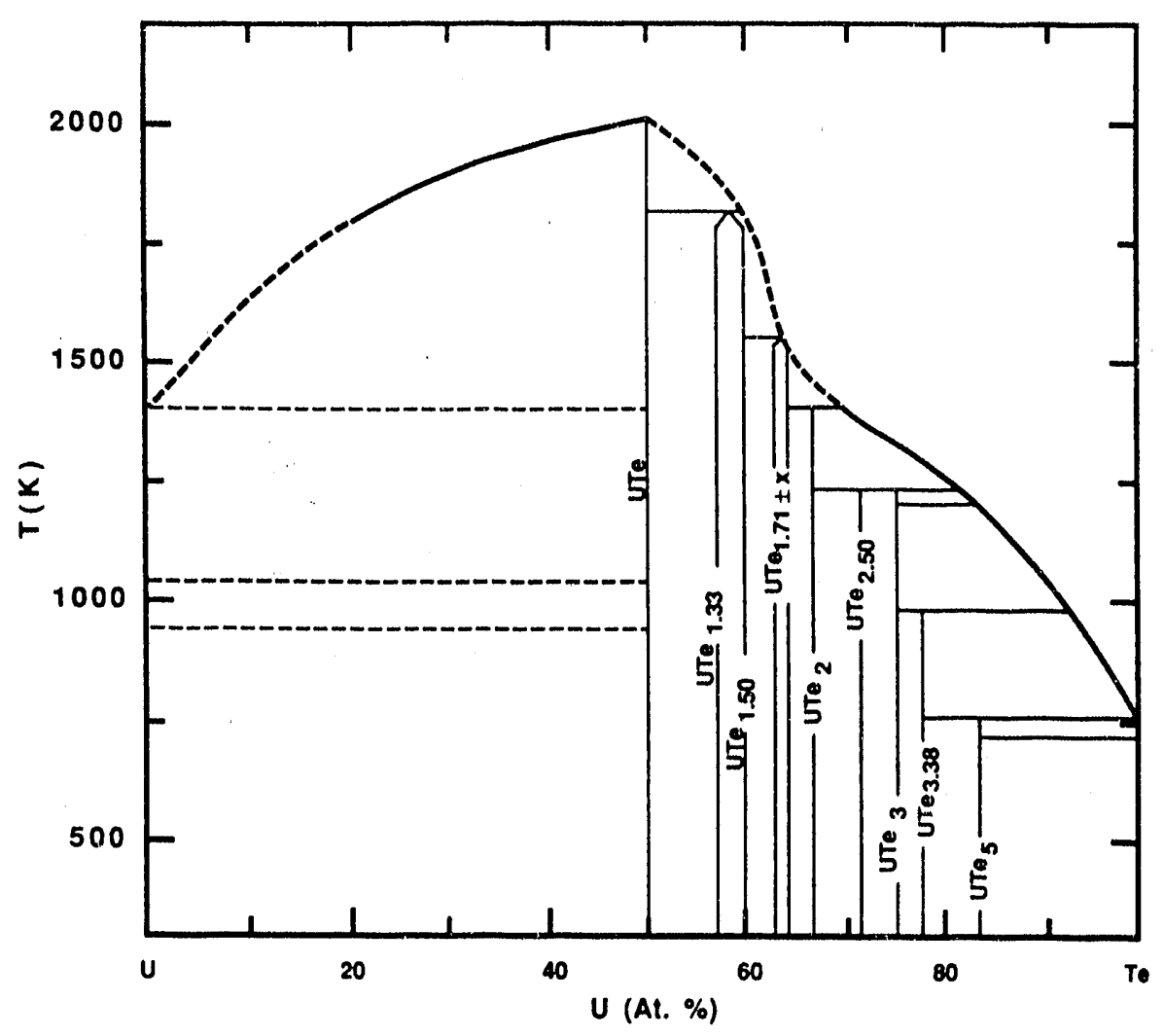

Figure 1: Phase diagram for the tellurium uranium system.

\section{Reported Phases in the U-Te System}

The principal tool in evaluating the proposed structural models and establishing powder diffraction standards will be the calculated powder diffraction pattern as computed using POWD10[26]. Calculation of the powder diffraction pattern simultaneously evaluates the structural model and the experimental powder diffraction pattern. Only the two most recent structural reports in this system have refined thermal motion parameters for the $\mathrm{U}$ and Te atoms $[22,21]$. In both studies an isotropic B of $1.0 \AA^{2}$ represents the motion of the uranium well. The tellurium has an average $B$ of about 1.3 $\AA^{2}$ in the $\mathrm{UTe}_{5}$ structure with one particularly anomalous value[21]. In the $\beta$-UTe $\mathrm{UT}_{3}$ structure, the three Te atoms each have a value of B near .5 $\AA^{2}[22]$. 
With only two structure determinations available for which B's have been determined, it is difficult to choose representative values to be used in the computations. We have assumed that the $\beta \mathrm{UTe}_{3}$ values of $1.0 \AA^{2}$ for uranium and $0.5 \AA^{2}$ for $\mathrm{Te}$ are the most representative and have used these values in all our computations except for the $\mathrm{UTe}_{5}$ and $\beta$-UTe $\mathrm{UT}_{3}$ structures where the published values are used. Anomalous dispersion corrections were applied to all atoms in the computations. A second essential tool in this investigation was the Crystal Data data base as published by the International Centre for Diffraction Data[30]. This, along with the NBS*LATTICE prooram of Himes and Mighell[19], proved invaluable in assessing isostructural models based on unit cell information.

Table 1 gives the metric information for the cells of the various $\mathrm{U}$-Te phases. In addition, the computed values for the density, linear absorption coefficient for $\mathrm{Cu} \mathrm{K}$ radiation, and the computed value for the reference Intensity Ratio $\mathrm{I} / \mathrm{I}_{c}$ are given. Table 3 gives the structural parameters used to obtain the calculated powder diffraction patterns. The occupancy values are as required by program POWD10, namely they are the fraction of the maximum occupancy allowed for the space group. They are followed by the Wykoff site notation . 


\begin{tabular}{|l|c|c|c|c|c|c|c|c|}
\hline Phase & Space 3roup & $\mathrm{a}(\AA)$ & $\mathrm{b}(\AA)$ & $\mathrm{c}(\AA)$ & $\alpha$ & $\beta$ & $\gamma$ & $\mathrm{Z}$ \\
\hline $\mathrm{UTe}[10]$ & Fm'sm & 6.160 & & & & & & 4 \\
$\mathrm{U}_{3} \mathrm{Te}_{4}[18]$ & $\mathrm{I} \overline{4} 3 \mathrm{~d}$ & $9.442[12]$ & & & & & & 3 \\
$\mathrm{U}_{2} \mathrm{Te}_{3}[18]$ & $\mathrm{I} \overline{4} 3 \mathrm{~d}$ & $9.390[12]$ & & & & & & 3 \\
$\mathrm{U}_{2} \mathrm{Te}_{3}[1]$ & $\mathrm{Pnma}$ & $12.32[34]$ & 4.45 & 11.83 & & & 4 \\
$\mathrm{U}_{7} \mathrm{Te}_{12}[4]$ & $\mathrm{P} 6_{3} / \mathrm{m}$ & 12.309 & & 4.242 & & & 1 \\
$\mathrm{UTe}_{1.78}[16]$ & $\mathrm{Immm}$ & $4.162[3]$ & 6.124 & 13.958 & & & 4 \\
$\mathrm{UTe}_{2}[16]$ & $\mathrm{Immm}$ & 4.16170 & 6.1276 & 13.9650 & & & 4 \\
$\alpha \mathrm{UTe}_{3}[29]$ & P2 $2 / \mathrm{m}$ & $6.090[3]$ & 4.226 & 10.302 & & 98 & & 12 \\
$\beta \mathrm{UTe}_{3}[22]$ & $\mathrm{Cmcm}$ & 4.338 & 24.743 & 4.338 & & & 4 \\
$\mathrm{UTe}_{5}[21]$ & Pnma & 17.9150 & 10.4070 & 4.2200 & & & 4 \\
\hline
\end{tabular}

Table 1: Space group and unit cells for the U-Te phases. 


\begin{tabular}{|l|c|c|c|c|}
\hline Phase & $\rho_{\text {obs }}$ & $\rho_{\text {cal }}$ & $\mu$ & $\mathrm{I} / \mathrm{I}_{c}$ \\
\hline $\mathrm{UTe}$ & $10.37[8]$ & 10.371 & 2053 & 21.142 \\
$\mathrm{U}_{3} \mathrm{Te}_{4}-$ cubic & $9.46[17]$ & 9.660 & 1997 & 15.70 \\
$\mathrm{U}_{2} \mathrm{Te}_{3}$ - cubic & $9.02[17]$ & 9.184 & 1933 & 14.36 \\
$\mathrm{U}_{2} \mathrm{Te}_{3}$ - orthorhombic & & 8.794 & 1851 & 5.04 \\
$\mathrm{U}_{7} \mathrm{Te}_{12}$ & & 9.54 & 2048 & 17.70 \\
$\mathrm{UTe}_{1.78}$ & & 9.68 & 1875 & 9.22 \\
$\mathrm{UTe}_{2}$ & & 9.20 & 2021 & 9.87 \\
$\alpha_{\mathrm{UTe}}$ & & 7.85 & 1826 & 9.78 \\
$\beta \mathrm{UTe}_{3}$ & & 8.86 & 2059 & 6.57 \\
$\mathrm{UTe}_{5}$ & & 7.39 & 1826 & 3.97 \\
\hline
\end{tabular}

Table 2: Physical constants for the U-Te phases. 


\begin{tabular}{|c|c|c|c|c|c|}
\hline Phase & Atom & $\mathrm{x}$ & $y$ & $z$ & Occupancy \\
\hline $\mathrm{UTe}[10]$ & U & 0.000000 & 0.000000 & 0.090000 & $.0208(100 \% 4 a)$ \\
\hline Cubic & $\mathrm{TE}$ & 0.500000 & 0.500000 & 0.500000 & $.0208(100 \% 4 b)$ \\
\hline $\mathrm{U}_{3} \mathrm{Te}_{4}[18]$ & U & $0.37 \div 300$ & 0.000000 & 0.250000 & $0.25(100 \% 12 \mathrm{a})$ \\
\hline Cubic & $\mathrm{Te}$ & 0.083330 & 0.083330 & 0.083330 & $0.3333(100 \% 16 c)$ \\
\hline $\mathrm{U}_{2} \mathrm{Te}_{3}[18]$ & U & 0.375000 & 0.000000 & 0.250000 & $0.2222(88.9 \% 12 \mathrm{a})$ \\
\hline Cubir & $\mathrm{Te}$ & 0.083330 & 0.083330 & 0.083330 & $0.3333(100 \% 16 c)$ \\
\hline $\mathrm{U}_{2} \mathrm{Te}_{3}[1]$ & U1 & 0.029300 & 0.250000 & 0.326100 & $.50(100 \% 4 c)$ \\
\hline \multirow[t]{4}{*}{ Orthorhombic } & U2 & 0.149500 & 0.750000 & 0.036000 & $.50(100 \% 4 c)$ \\
\hline & Te1 & 0.049700 & 0.250000 & 0.876900 & $.50(100 \% 4 c)$ \\
\hline & $\mathrm{Te} 2$ & 0.125100 & 0.750000 & 0.438600 & $.50(100 \% 4 \mathrm{c})$ \\
\hline & $\mathrm{Te} 3$ & 0.207900 & 0.250000 & 0.191700 & $.50(100 \% 4 c)$ \\
\hline $\mathrm{U}_{7} \mathrm{Te}_{12}[4]$ & U1 & $0.0<5000$ & 0.000000 & 0.250000 & $.0833(17 \% 2 a)$ \\
\hline \multirow[t]{3}{*}{ Hexagonal } & U2 & 0.150000 & 0.280000 & 0.250000 & $.5000(100 \% 6 \mathrm{~h})$ \\
\hline & Tel & 0.510000 & 0.380000 & 0.250000 & $.5000(100 \% 6 \mathrm{~h})$ \\
\hline & $\mathrm{Te} 2$ & 0.240000 & 0.000000 & 0.250000 & $.5000(100 \% 6 \mathrm{~h})$ \\
\hline $\mathrm{UTe}_{1.78}[16]$ & $\mathrm{U}$ & 0.000000 & 0.000000 & 0.134800 & $.25(100 \% 4 \mathrm{i})$ \\
\hline \multirow[t]{2}{*}{ Orthorhombic } & TE1 & 0.300000 & 0.000000 & 0.297700 & $.2225(89 \% 4 \mathrm{j})$ \\
\hline & TE2 & 0.000000 & $J .251000$ & 0.500000 & $.2225(89 \% 4 h)$ \\
\hline
\end{tabular}

Table 3: Atom locations and site occupancy. 


\begin{tabular}{|c|c|c|c|c|c|}
\hline $\mathrm{UTe}_{2}[16]$ & U & 0.000000 & 0.000000 & 0.134800 & $.25(100 \%$ ii $)$ \\
\hline \multirow[t]{2}{*}{ Orthorhombic } & TE1 & 0.500000 & 0.000000 & 0.297700 & $.25(10 \mathrm{j} \% 4 \mathrm{j})$ \\
\hline & TE2 & 0.000000 & 0.251000 & 0.500000 & $.25(100 \% 4 h)$ \\
\hline$\alpha \mathrm{UTe}_{3}[29]$ & U & 0.373230 & 0.250000 & 0.156020 & $.50(100 \% 2 \mathrm{e})$ \\
\hline \multirow[t]{3}{*}{ Monoclinic } & $\mathrm{Te} 1$ & 0.799100 & 0.250000 & 0.063200 & $.50(100 \% 2 \mathrm{e})$ \\
\hline & Te2 & 0.704200 & 0.250000 & 0.667900 & $.50(100 \% 2 \mathrm{e})$ \\
\hline & $\mathrm{Te} 3$ & 0.279900 & 0.250000 & 0.659100 & $.50(100 \% 2 \mathrm{e})$ \\
\hline$\beta \mathrm{UTe}_{3}[22]$ & $\mathrm{U}$ & 0.000000 & 0.833100 & 0.250000 & $.25(100 \% 4 \mathrm{c})$ \\
\hline \multirow[t]{3}{*}{ Orthorhombic } & Te1 & 0.000000 & 0.072000 & 0.250000 & $.25(100 \% 4 c)$ \\
\hline & $\mathrm{Te} 2$ & 0.000000 & 0.427700 & 0.250000 & $.25(100 \% 4 \mathrm{c})$ \\
\hline & Te3 & 0.000000 & 0.703900 & 0.250000 & $.25(100 \% 4 c)$ \\
\hline $\mathrm{UTe}_{5}[21]$ & $\mathrm{U}$ & 0.407930 & 0.250000 & 0.386100 & $.5(100 \% 4 c)$ \\
\hline \multirow[t]{4}{*}{ Orthorhombic } & $\mathrm{Te} 1$ & 0.163840 & 0.565200 & 0.387900 & $.5(100 \% 8 \mathrm{~d})$ \\
\hline & $\mathrm{Te} 2$ & 0.040800 & 0.250000 & 0.621100 & $.5(100 \% 4 c)$ \\
\hline & $\mathrm{Te} 3$ & 0.739900 & 0.250000 & 0.354000 & $.5(100 \% 4 c)$ \\
\hline & Te4 & 0.000000 & 0.000000 & 0.000000 & $.5(100 \% 4 \mathrm{c})$ \\
\hline
\end{tabular}

Table 3: (continued). A tom locations and site occupancy. 


\section{UTe}

This phase was first reported by Ferro[10] to be a cubic $\mathrm{NaCl}$ structure. It has since been reported by many authors but surprisingly, no one has ever published a powder pattern for this phase. The average lattice parameter from the many reports is about $6.160 \AA$. A calculated powder pattern done at NBS exists in the Powder Diffraction File (PDF) as pattern number 15856. Calculating the structure as an $\mathrm{NaCl}$ type with space group $\mathrm{Fm} 3 \mathrm{~m}$ and $\mathrm{a}=6.160 \AA$ gives the expected good agreement with the NBS calculated pattern PDF 15-856 as shown in Table 4. 


\begin{tabular}{|c|c|c|c|c|c|}
\hline $\mathrm{d}$ & $\mathrm{I}^{\mathrm{rel}}$ & $\begin{array}{c}\text { Calculated } \\
\text { hk } \ell\end{array}$ & d & $\mathrm{I}^{\mathrm{rel}}$ & $\begin{array}{c}\text { PDF } 15-856 \\
\text { hk } \ell\end{array}$ \\
\hline 3.556 & 13 & 111 & 3.56 & 18 & 111 \\
\hline 3.080 & 100 & 200 & 3.08 & 100 & 200 \\
\hline 2.178 & 68 & 220 & 2.18 & 70 & 220 \\
\hline 1.8573 & 5 & $\begin{array}{lll}31 & 1\end{array}$ & 1.858 & 8 & $\begin{array}{lll}3 & 1 & 1\end{array}$ \\
\hline 1.7782 & 23 & 222 & 1.779 & 25 & 222 \\
\hline 1.5400 & 10 & 400 & 1.541 & 10 & 400 \\
\hline 1.4132 & 2 & 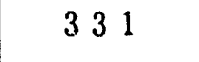 & 1.414 & 4 & 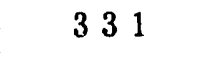 \\
\hline 1.3774 & 25 & 420 & 1.378 & 25 & 420 \\
\hline 1.2574 & 18 & 422 & 1.258 & 20 & 422 \\
\hline 1.1855 & 1 & 511 & 1.186 & 2 & 511 \\
\hline 1.0889 & 5 & 440 & 1.089 & 6 & 440 \\
\hline 1.0412 & 1 & 531 & 1.042 & 2 & 531 \\
\hline 1.0267 & 11 & $600+$ & 1.027 & 14 & 600 \\
\hline 0.9740 & 8 & 620 & 0.974 & 10 & 620 \\
\hline 0.9394 & $<1$ & 533 & 0.940 & 2 & 533 \\
\hline 0.9287 & 7 & 622 & 0.929 & 10 & 622 \\
\hline 0.8891 & 2 & 444 & 0.890 & 4 & 444 \\
\hline 0.8626 & 1 & $711+$ & 0.863 & 2 & 711 \\
\hline 0.8542 & 7 & 640 & 0.855 & 10 & 640 \\
\hline 0.8232 & 13 & 642 & 0.824 & 18 & 642 \\
\hline 0.8020 & 1 & $731+$ & 0.802 & 4 & 731 \\
\hline
\end{tabular}

Table 4: Calculated (left) and the NBS calculated (right) PDF pattern (15856) for UTe. 


\section{$4 \mathrm{U}_{3} \mathrm{Te}_{4}\left(\mathrm{UTe}_{1.333}\right)$}

\section{1 $\mathrm{U}_{3} \mathrm{Te}_{4}-\mathrm{Cubic}$}

Ferro[10] described $\mathrm{U}_{3} \mathrm{Te}_{4}$ and proposed a cubic structure, isostructural with $\mathrm{Th}_{3} \mathrm{P}_{4}$. There is a solid solution region covering the range $\mathrm{UTe}_{1.333}$ to $\mathrm{UTe}_{1.5}$ in the phase diagram. 'The cubic cell stretches from $9.442[12] \AA$ on the U rich $\varepsilon$. . to $9.390[12] \AA$ on the Te rich side. Most authors (see [13]) report the lattice parameter closer to $9.410 \AA$ or the $9.40 \AA$ originally reported by Ferro and available as PDF pattern 12-610. We have calculated the end members using the $\mathrm{Th}_{3} \mathrm{P}_{4}$ structure as determined by Meisel[18]. Since we calculated the end members of this series, the $d^{\prime s}$ in our patterns are shifted from the PDF values, as shown in Table 5. The agreement of our calculated intensities with the data of Ferro, indicates that the overall structure model chosen, is correct. However, the calculated density of $9.660 \mathrm{~g} / \mathrm{cm}^{3}$ is somewhat larger than the $9.46 \mathrm{~g} / \mathrm{cm}^{3}$ reported by Matson, Moody and Himes[17]. This indicates that the samples that most researchers have reported as $\mathrm{U}_{3} \mathrm{Te}_{4}$ were probably uranium deficient. The $\mathrm{U}$ and Te atomic positions are given in Table 3. These sites are fully occupied in the ideal $\mathrm{U}_{3} \mathrm{Te}_{4}$ stoichiometry. 


\begin{tabular}{|c|c|c|c|c|c|}
\hline $\mathrm{d}$ & $\mathrm{I}^{\mathrm{rel}}$ & $\begin{array}{c}\text { Calculated } \\
\text { hk } \ell\end{array}$ & $\mathrm{d}$ & Irel & $\begin{array}{c}\text { PDF } 12-610 \\
\text { hk } \ell\end{array}$ \\
\hline 3.855 & 28 & 211 & 3.804 & 30 & 211 \\
\hline 3.338 & 2 & 220 & & & \\
\hline 2.986 & 100 & $\begin{array}{lll}31 & 0\end{array}$ & 2.945 & 100 & $\begin{array}{lll}310 & 0\end{array}$ \\
\hline 2.523 & 77 & 321 & 2.500 & 80 & 321 \\
\hline 2.111 & 23 & 420 & 2.091 & 50 & 420 \\
\hline 2.013 & 15 & 332 & 1.995 & 40 & 332 \\
\hline 1.9273 & 12 & 422 & 1.9080 & 40 & 422 \\
\hline 1.8517 & 12 & 431 & 1.8350 & 50 & 510 \\
\hline 1.7239 & 6 & 521 & 1.7120 & 10 & 521 \\
\hline & & & 1.6720 & 10 & 440 \\
\hline 1.6193 & 2 & 530 & & & \\
\hline 1.5317 & 25 & $532+$ & 1.5190 & 80 & 611 \\
\hline 1.4929 & 8 & 620 & 1.4820 & 40 & 620 \\
\hline 1.4569 & 13 & 541 & 1.4460 & 50 & 541 \\
\hline 1.3922 & 5 & 631 & 1.3790 & 30 & 631 \\
\hline 1.3628 & 5 & 444 & 1.3530 & 40 & 444 \\
\hline 1.3353 & 3 & $543+$ & 1.3230 & 20 & 710 \\
\hline 1.3094 & 4 & 640 & 1.2980 & 30 & 640 \\
\hline 1.2849 & 12 & $721+$ & 1.2760 & 90 & 721 \\
\hline 1.2617 & 4 & 642 & 1.2540 & 40 & 642 \\
\hline 1.1991 & 2 & 651 & 1.1890 & 30 & 651 \\
\hline 1.1803 & 1 & 800 & 1.1720 & 5 & 800 \\
\hline
\end{tabular}

Table 5: Calculated (left) and the observed (12-610) powder pattern for cubic $\mathrm{U}_{3} \mathrm{Te}_{4}$. 


\begin{tabular}{|c|c|c|c|c|c|}
\hline$d$ & $\mathrm{I}^{r e l}$ & $\begin{array}{c}\text { Calculated } \\
\text { hk } \ell\end{array}$ & d & $\mathrm{I}^{\mathrm{rel}}$ & $\begin{array}{c}\text { PDF } 12-610 \\
\text { hk } \ell\end{array}$ \\
\hline 1.1622 & 1 & 741 & 1.1550 & 5 & 741 \\
\hline 1.1285 & 1 & 653 & 1.1220 & 40 & 653 \\
\hline \multirow[t]{2}{*}{1.1128} & 3 & $822+$ & 1.1150 & 10 & 822 \\
\hline & & & 1.1060 & 40 & 660 \\
\hline 1.0976 & 7 & $743+$ & 1.0910 & 70 & 750 \\
\hline 1.0691 & 4 & 752 & 1.0630 & 50 & 752 \\
\hline 1.0556 & 1 & 840 & 1.0500 & 20 & 840 \\
\hline 1.0302 & 3 & 842 & 1.0250 & 60 & 842 \\
\hline 1.0182 & 11 & $921+$ & 1.0130 & 100 & 921 \\
\hline 0.9953 & 6 & $851+$ & .99000 & 100 & 851 \\
\hline 0.9739 & 2 & $763+$ & & & \\
\hline 0.9637 & 2 & 844 & & & \\
\hline 0.9538 & 2 & $853+$ & & & \\
\hline 0.9349 & 4 & $772+$ & & & \\
\hline 0.9171 & 3 & $950+$ & & & \\
\hline 0.9003 & 2 & 765 & & & \\
\hline 0.8843 & 1 & 871 & & & \\
\hline 0.8767 & 4 & $864+$ & & & \\
\hline 0.8692 & 2 & $1033+$ & & & \\
\hline 0.8619 & 2 & 1042 & & & \\
\hline 0.8548 & 4 & $873+$ & & & \\
\hline
\end{tabular}

Table 5: (continued). Calculated (left) and the observed (12-610) powder pattern for cubic $\mathrm{U}_{3} \mathrm{Te}_{4}$. 


\begin{tabular}{|r|r|c|r|r|r|}
\hline $\mathrm{d}$ & $\mathrm{I} \mathrm{I}^{\text {rel }}$ & $\begin{array}{c}\text { halculated } \\
\mathrm{hk} \ell\end{array}$ & $\mathrm{d}$ & $\mathrm{Irei}$ & $\begin{array}{c}\text { PDF 12-610 } \\
\mathrm{hk} \ell\end{array}$ \\
\hline 0.8412 & 1 & $963+$ & & & \\
0.8346 & 2 & 880 & & & \\
0.8281 & 1 & $970+$ & & & \\
0.8157 & 7 & $1053+$ & & & \\
0.8096 & 3 & $1060+$ & & & \\
0.8038 & 2 & $1141+$ & & & \\
0.7924 & 1 & 965 & & & \\
0.7868 & 2 & $884+$ & & & \\
0.7814 & 3 & $974+$ & & & \\
\hline
\end{tabular}

Table 5: (continued). Calculated (left) and the observed (12-610) powder pattern for cubic $\mathrm{U}_{3} \mathrm{Te}_{4}$. 


\section{2 $\mathrm{U}_{3} \mathrm{Te}_{4}$-Orthorhombic}

There is also an orthorhombic phase with the stoichiometry $\mathrm{U}_{3} \mathrm{Te}_{4}[34]$. This is a defect material which has the stibnite $\left(\mathrm{Sb}_{2} \mathrm{~S}_{3}\right)$ structure. The stoicinometric material, with all lattice sites filled has the formula $\mathrm{U}_{2} \mathrm{Te}_{3}$ and is discussed in detail below. The lattice parameters for the orthorhombic $\mathrm{U}_{3} \mathrm{Te}_{4}$ phase have been determined and are give in Table 7. No powder pattern has ever been published for this phase. However, since our assessment of the reported lattice parameters (Table 7) shows that they do not vary much across the solid solution range and since a small uranium deficiency will not greatly effect the intensities, the powder patterns for this series should not vary much.

The stibnite structure (orthorhombic $\mathrm{U}_{3} \mathrm{Te}_{4}$ ), shown in Table 3 has two independent uranium atoms and three independent telluriums. Even though it may be reasonable to assume that the uranium sublattice is more likely to have vacancies, there is no way of establishing which uranium site or sites receives the vacancies without a Rietveld refinement of a good powder pattern. Unili such a pattern and refined model is available, there is no justification for the calculation of any patterns on this side of the solid solution. 


\section{$5 \quad \mathrm{U}_{2} \mathrm{Te}_{3}\left(\mathrm{UTe}_{1.5}\right)$}

\section{$5.1 \quad \mathrm{U}_{2} \mathrm{Te}_{3}-\mathrm{Cubic}$}

This phase represents the $c$ ther side of the solid solution range from $\mathrm{UTe}_{1.33}$ to $\left(\mathrm{UTe}_{1.5}\right)$. L. K. Matson et al.[17] have measured the density of this $\mathrm{Th}_{3} \mathrm{P}_{4}$ structure type on both sides of the solid solution range to be $9.46 \mathrm{~g} / \mathrm{cm}^{3}$ on the high uranium side $\left(\mathrm{U}_{3} \mathrm{Te}_{4}\right)$ and $9.02 \mathrm{~g} / \mathrm{cm}^{3}$ on the high tellurium side $\left(\mathrm{U}_{2} \mathrm{Te}_{3}\right)$. They report the lattice parameter for each of these phasrs to be equal at $9.397 \AA$. We choose to use $9.390 \AA[12]$ which is close to the value reported by most other authors for tius phase see [13].

No powder pattern for the $\mathrm{U}_{2} \mathrm{Te}_{3}$ cubic defect phase has ever been published. To simulate this pattern we assumed that the vacancies go to the single uranium site in the lattice. In the $3: 4$ stoichiometry, all sites are completely filled. The $2: 3$ stoichiometry is most easily achieved by leaving the Te sites filled and placing $88.8 \%$ of a uranium atom on each site. Any other model will require placing vacancies on both the Te and $U$ sites. Zachariasen[35] also proposed the uranium defect model, however, Carter[7] suggests that some degree of cation vacancy pairing should occur. Since this will not effect the powder pattern (assuming no superlattice exists), we ignore this possibility in our model. The uranium vacancy model produces a calculated density of $9.184 \mathrm{~g} / \mathrm{cm}^{3}$. This is reasonably close to the value of $9.02 \mathrm{~g} / \mathrm{cm}^{3}$ reported by Matson, Moody and Himes[17]. The calculated pattern shown in Table 6 is compared to the only available pattern in this 
system-namely the other side of the solid solution, $\mathrm{U}_{3} \mathrm{Te}_{4}[10]$. 


\begin{tabular}{|c|c|c|c|c|c|}
\hline d & $\mathrm{I}^{r e l}$ & $\begin{array}{c}\text { Calculated } \\
\text { hk } \ell\end{array}$ & d & $I^{r e l}$ & $\begin{array}{c}\text { PDF } 12-610 \\
\text { hk } \ell\end{array}$ \\
\hline 3.833 & 21 & 211 & 3.804 & 30 & 211 \\
\hline 3.320 & 1 & 220 & & & \\
\hline 2.969 & 100 & $\begin{array}{lll}31 & 0\end{array}$ & 2.945 & 100 & 310 \\
\hline 2.510 & 79 & 321 & 2.500 & 80 & 321 \\
\hline 2.100 & 20 & 420 & 2.091 & 50 & 420 \\
\hline 2.002 & 13 & 332 & 1.995 & 40 & 332 \\
\hline 1.9167 & 13 & 422 & 1.9080 & 40 & 422 \\
\hline 1.8415 & 11 & 431 & 1.8350 & 50 & 510 \\
\hline \multirow[t]{2}{*}{1.7144} & 5 & 521 & 1.7120 & 10 & 521 \\
\hline & & & 1.6720 & 10 & 440 \\
\hline 1.6104 & 3 & 530 & & & \\
\hline 1.5233 & 24 & 532 & 1.5190 & 80 & 611 \\
\hline 1.4847 & 8 & 620 & 1.4820 & 40 & 620 \\
\hline 1.4489 & 13 & 541 & 1.4460 & 50 & 541 \\
\hline 1.3845 & 5 & 631 & 1.3790 & 30 & 631 \\
\hline 1.3553 & 5 & 444 & 1.3530 & 40 & 444 \\
\hline 1.3280 & 4 & 543 & 1.3230 & 20 & 710 \\
\hline 1.3022 & 3 & 640 & 1.2980 & 30 & 640 \\
\hline 1.2778 & 11 & 721 & 1.2760 & 90 & 721 \\
\hline 1.2548 & 4 & 642 & 1.2540 & 40 & 642 \\
\hline \multirow[t]{2}{*}{1.1925} & 2 & 651 & 1.1890 & 30 & 651 \\
\hline & & & 1.1720 & 5 & 800 \\
\hline
\end{tabular}

Table 6: Calculated pattern for cubic $\mathrm{U}_{2} \mathrm{Te}_{3}$ (left) and the observed (12-610) pattern for $\mathrm{U}_{3} \mathrm{Te}_{4}$. 


\begin{tabular}{|c|c|c|c|c|c|}
\hline d & $\mathrm{I}^{\mathrm{rel}}$ & $\begin{array}{c}\text { Calculated } \\
\text { hk } \ell\end{array}$ & d & Irel & $\begin{array}{c}\text { FDF } 12-610 \\
\text { hk } \ell\end{array}$ \\
\hline 1.1558 & 1 & 741 & 1.1550 & 5 & 741 \\
\hline 1.1223 & 1 & 653 & 1.1220 & 40 & 653 \\
\hline \multirow[t]{2}{*}{1.1066} & 3 & 822 & 1.1150 & 10 & 822 \\
\hline & & & 1.1060 & 40 & 832 \\
\hline 1.0816 & 7 & 743 & 1.0910 & 70 & 750 \\
\hline 1.0632 & 4 & 752 & 1.0630 & 50 & 752 \\
\hline 1.0498 & 1 & 840 & 1.0500 & 20 & 840 \\
\hline 1.0369 & 1 & 910 & 1.0250 & 60 & 842 \\
\hline 1.0245 & 3 & 842 & 1.0130 & 100 & 921 \\
\hline 1.0125 & 11 & 921 & .99000 & 100 & 851 \\
\hline 0.9898 & 6 & 851 & & & \\
\hline 0.9685 & 2 & 763 & & & \\
\hline 0.9584 & 2 & 844 & & & \\
\hline 0.9485 & 2 & 853 & & & \\
\hline 0.9298 & 4 & 772 & & & \\
\hline 0.9120 & 3 & 950 & & & \\
\hline 0.8953 & 2 & 765 & & & \\
\hline 0.8795 & 1 & 871 & & & \\
\hline 0.8718 & 3 & $864+$ & & & \\
\hline 0.8644 & 1 & $1033+$ & & & \\
\hline 0.8572 & 2 & 1042 & & & \\
\hline 0.8501 & 4 & $873+$ & & & \\
\hline
\end{tabular}

Taule 6: (continued). Calculated pattern for cubic $\mathrm{U}_{2} \mathrm{Te}_{3}$ (left) and the observed (12-610) pattern for $\mathrm{U}_{3}\left[\mathrm{Te}_{4}\right.$. 


\begin{tabular}{|c|c|c|c|c|c|}
\hline d & $\mathrm{I}^{\mathrm{rel}}$ & $\begin{array}{c}\text { Calculated } \\
\text { hk } \ell\end{array}$ & $d$ & $\mathrm{I}^{\mathrm{rel}}$ & $\begin{array}{c}\text { PDF } 12-610 \\
\text { hk } \ell\end{array}$ \\
\hline 0.8365 & 1 & $963+$ & & & \\
\hline 0.8300 & 2 & 880 & & & \\
\hline 0.8236 & 1 & $970+$ & & & \\
\hline 0.8112 & 7 & $1053+$ & & & \\
\hline 0.8052 & 3 & $1060+$ & & & \\
\hline 0.7993 & 2 & $1141+$ & & & \\
\hline 0.7880 & 1 & 965 & & & \\
\hline 0.7825 & 2 & $884+$ & & & \\
\hline 0.7771 & 3 & $974+$ & & & \\
\hline
\end{tabular}

Table 6: (continued). Calculated pattern for cubic $\mathrm{U}_{2} \mathrm{Te}_{3}$ (left) and the observed (12-610) pattern for $\mathrm{U}_{3} \mathrm{Te}_{4}$. 


\section{2 $\mathrm{U}_{2} \mathrm{Te}_{3}$-Orthorhombic}

Ferro[10] ar.d later Suski et al.[32] report that an orthorhombic phase also covers the same phase region as the cubic $\mathrm{U}_{3} \mathrm{Te}_{4}$ (i.e. $\mathrm{UTe}_{1.33}$ ) to $\mathrm{U}_{2} \mathrm{Te}_{3}$ (i.e. $\left.\mathrm{UTe}_{1.5}\right)$. Suski and Janus[34] showed that the orthorhombic modification is the stable variety while the cubic form is a high temperature metastable modification. Suski[32] in 1976 gave the lattice parameters of the end mambers of the solid solution as shown in Table 7. In 1980 he and Janus[34] showed that in fact, both end members had the same lattice parameters. The values we have used are from the orthorhombic $\mathrm{U}_{2} \mathrm{Te}_{3}$ shown in Table 1.

These phases are reported to be isostructural with $\mathrm{U}_{2} \mathrm{~S}_{3}$ and $\mathrm{U}_{2} \mathrm{Se}_{3}$ by Suski[32]. This has been confirmed by Slovyanskikh et al.[28] who reported $\mathrm{U}_{2} \mathrm{Te}_{3}$ as isostructural with $\mathrm{Sb}_{2} \mathrm{~S}_{3}$.

The "ideal" structure for the $\mathrm{U}_{2} \mathrm{Te}_{3}$ stoichiometry is that of $\mathrm{Sb}_{2} \mathrm{~S}_{3}$ (stibnite). This model fills the two independent uranium sites and the three independent tellurium sites. This structure goes nonstoichiometric (probably on the cation sublattice) to give the orthorhombic form of $U_{3} \mathrm{Te}_{4}$ discussed above. Our calculated density for the orthorhombic form of $\mathrm{U}_{2} \mathrm{Te}_{3}$ is 8.749 $\mathrm{g} / \mathrm{cm}^{3}$.

A problem here is to establish which axis $(11.86 \AA$ and $12.46 \AA)$ is a and which is the $c$ axis. The isostructural $\mathrm{Sb}_{2} \mathrm{~S}_{3}$ structure has a and $\mathrm{c}$ nearly identiral, and the related structures $\mathrm{Th}_{2} \mathrm{~S}_{3}, \mathrm{U}_{2} \mathrm{~S}_{3}$ and $\mathrm{Np}_{2} \mathrm{~S}_{3}[35]$ have no clear trend indicating which should be longer. Calculated U-Te distances 


\begin{tabular}{|c|c|c|c|c|}
\hline Phase & Reference & $\mathrm{a}(\AA)$ & $\mathrm{b}(\AA)$ & $\mathrm{c}(\AA)$ \\
\hline $\mathrm{U}_{2} \mathrm{Te}_{3}$ & Suski 1980[34] & 11.83 & 4.45 & 12.31 \\
$\mathrm{U}_{2} \mathrm{Te}_{3}$ & Suski 1976[32] & 11.79 & 4.433 & 12.34 \\
$\mathrm{U}_{2} \mathrm{Te}_{3}$ & Slovyanskikh 1977[28] & 11.71 & 4.36 & 12.22 \\
$\mathrm{U}_{3} \mathrm{Te}_{4}$ & Suski 1976[32] & 11.86 & 4.401 & 12.46 \\
$\mathrm{U}_{3} \mathrm{Te}_{4}$ & Suski $1980[34]$ & 11.83 & 4.45 & 12.33 \\
\hline
\end{tabular}

Table 7: Lattice parameters for the orthorhombic $\mathrm{U}_{2} \mathrm{Te}_{3}-\mathrm{U}_{3} \mathrm{Te}_{4}$ solid solution range.

with the axis in each orientation produce a weak argument: with $\mathrm{a}=12.46 \AA$ and $c=11.86 \AA$, the distance from $U 1$ to $T e 3$ is closer to the distance from $\mathrm{U} 1$ to Te2. In addition, the powder patterns agree a bit better with the axis chosen this way. This very weak argument leads us to choose the orientation given in Table 1.

We should also note how poorly the current PDF pattern for $\mathrm{U}_{2} \mathrm{Te}_{3}$ $(34-807)[28]$ and the deleted pattern (21-1408)[27] match each other or the calculated pattern shown in Table 8. For a number of reasons (even with the doubt about the model mentioned above), we prefer to use the calculated pattern as representative of this phase until an experimen'al pattern becomes available. As socn as an adequate experimental pattern is available we suggest that a Rietveld refinement be carried out to establish more firmly the orientation of the a and $c$ axis and much more importantly, to refine the 
$x, y$ and $z$ values of the $U$ and Te atoms. It is clear from Zachariasen's[35] work that these values vary considerably among the isostructural materials. The powder pattern calculated with the a and $\mathrm{c}$ axis reversed are not so different that a phase identification would not treat them as identical. 


\begin{tabular}{|c|c|c|c|c|c|c|}
\hline $\mathrm{d}$ & $\mathrm{I}^{\text {rel }}$ & $\begin{array}{c}\text { Calculated } \\
\text { hk } \ell\end{array}$ & $\begin{array}{c}\text { PDF 34-807 } \\
\text { d }\end{array}$ & $\mathrm{I}^{\mathrm{rel}}$ & $\begin{array}{c}\text { PDF 21-1408 } \\
\mathrm{d}\end{array}$ & $I^{r e l}$ \\
\hline 8.533 & 8 & 101 & & & & \\
\hline 6.160 & 18 & 200 & & & & \\
\hline 5.915 & 5 & 002 & & & & \\
\hline 5.464 & 49 & 201 & & & & \\
\hline 5.332 & 2 & 102 & & & & \\
\hline 4.267 & 8 & 202 & & & & \\
\hline 4.165 & 13 & $\begin{array}{lll}0 & 1 & 1\end{array}$ & & & & \\
\hline 3.946 & 2 & 111 & & & & \\
\hline 3.880 & 22 & 301 & & & & \\
\hline 3.756 & 17 & 103 & & & 3.74 & 20 \\
\hline 3.607 & 8 & 210 & & & & \\
\hline 3.417 & 71 & 112 & & & & \\
\hline 3.373 & 43 & 302 & 3.386 & 30 & 3.35 & 20 \\
\hline 3.321 & 12 & 203 & & & & \\
\hline \multirow[t]{2}{*}{3.080} & 100 & 212 & 3.058 & 50 & & \\
\hline & & & 2.984 & 30 & & \\
\hline 2.951 & 62 & 013 & 2.967 & 40 & 2.96 & 10 \\
\hline 2.870 & 24 & 113 & & & & \\
\hline \multirow[t]{2}{*}{2.844} & 4 & $\begin{array}{lll}303 \\
\end{array}$ & 2.849 & 80 & 2.83 & 10 \\
\hline & & & 2.821 & 70 & & \\
\hline 2.732 & 40 & 402 & & & 2.72 & 100 \\
\hline 2.688 & 34 & 312 & & & & \\
\hline
\end{tabular}

Table 8: Calculated and PDF patterns (34-807 and 21-1408) for $\mathrm{U}_{2} \mathrm{Te}_{3}$. 


\begin{tabular}{|c|c|c|c|c|c|c|}
\hline$d$ & Irel & $\begin{array}{c}\text { Calculated } \\
\text { hk } \ell\end{array}$ & $\begin{array}{c}\text { PDF 34-807 } \\
\text { d }\end{array}$ & $I^{r e l}$ & $\begin{array}{c}\text { PDF 21-1408 } \\
\mathrm{d}\end{array}$ & $\mathrm{I}^{\text {rel }}$ \\
\hline 2.666 & 14 & 204 & 2.652 & 100 & 2.51 & 40 \\
\hline 2.533 & 16 & 410 & & & & \\
\hline 2.476 & 26 & 411 & & & & \\
\hline 2.427 & 5 & 403 & & & & \\
\hline 2.415 & 10 & $114+$ & & & & \\
\hline 2.397 & 8 & $313+$ & 2.392 & 30 & & \\
\hline 2.328 & 5 & 412 & & & 2.33 & 20 \\
\hline 2.324 & 5 & 105 & & & & \\
\hline 2.287 & 16 & 214 & 2.301 & 30 & & \\
\hline 2.275 & 14 & 502 & & & 2.27 & 10 \\
\hline 2.225 & 45 & 020 & & & & \\
\hline 2.209 & 14 & 205 & 2.181 & 30 & 2.212 & 30 \\
\hline 2.153 & 1 & 121 & & & & \\
\hline 2.131 & 10 & $413+$ & & & & \\
\hline 2.121 & 10 & 511 & & & & \\
\hline 2.112 & 27 & 314 & & & & \\
\hline 2.089 & 22 & 015 & & & & \\
\hline 2.061 & 8 & 221 & & & & \\
\hline 2.050 & 19 & $305+$ & 2.045 & 40 & 2.00 & 20 \\
\hline 2.023 & 3 & $601+$ & & & & \\
\hline 1.9717 & 4 & $006+$ & & & & \\
\hline 1.9469 & 5 & 106 & & & & \\
\hline
\end{tabular}

Cable 8: (continued). Calculated and PDF patterns (34-807 and 21-1408) for $\mathrm{U}_{2} \mathrm{Te}_{3}$. 


\begin{tabular}{|c|c|c|c|c|c|c|}
\hline$d$ & $\mathrm{I}^{\mathrm{rel}}$ & $\begin{array}{c}\text { Calculated } \\
\text { hk } \ell\end{array}$ & $\begin{array}{c}\text { PDF } 34-807 \\
\mathrm{~d}\end{array}$ & $I^{r e l}$ & $\begin{array}{c}\text { PDF 21-1408 } \\
d\end{array}$ & $\mathrm{I}^{\mathrm{rel}}$ \\
\hline 1.9398 & 4 & 602 & & & & \\
\hline 1.9301 & 6 & 321 & & & & \\
\hline 1.9237 & 5 & 414 & & & & \\
\hline 1.9143 & 5 & 123 & & & & \\
\hline 1.8915 & 6 & 513 & & & • & \\
\hline 1.8644 & 44 & $610+$ & & & 1.87 & 80 \\
\hline 1.8212 & 10 & 603 & & & & \\
\hline 1.8036 & 6 & 420 & & & & \\
\hline 1.7830 & 1 & 421 & & & & \\
\hline 1.7780 & 1 & $024+$ & & & & \\
\hline 1.7525 & 1 & 323 & & & & \\
\hline 1.7420 & 1 & 514 & & & & \\
\hline 1.7252 & 20 & $422+$ & & & & \\
\hline 1.7083 & 6 & 224 & & & & \\
\hline 1.6869 & 3 & $702+$ & & & 1.69 & 100 \\
\hline 1.6743 & 1 & 107 & & & & \\
\hline 1.6606 & 3 & 406 & & & & \\
\hline 1.6506 & 1 & 316 & & & & \\
\hline 1.6402 & 2 & 423 & & & & \\
\hline 1.6298 & 10 & $207+$ & & & & \\
\hline 1.6212 & 3 & 711 & & & & \\
\hline 1.6072 & 6 & $703+$ & & & 1.61 & 70 \\
\hline
\end{tabular}

Table 8: (continued). Calculated and PDF patterns (34-807 and 21-1408) for $\mathrm{U}_{2} \mathrm{Te}_{3}$. 


\begin{tabular}{|c|c|c|c|c|c|c|}
\hline$d$ & $I^{r e l}$ & $\begin{array}{c}\text { Calculated } \\
\text { hk } \ell\end{array}$ & $\begin{array}{c}\text { PDF 34-807 } \\
\mathrm{d}\end{array}$ & $\mathrm{I}^{\mathrm{rel}}$ & $\begin{array}{c}\text { PDF 21-1408 } \\
\text { d }\end{array}$ & $\mathrm{I}^{\mathrm{rel}}$ \\
\hline 1.5905 & 7 & 522 & & & & \\
\hline 1.5799 & 2 & 017 & & & 1.58 & 20 \\
\hline 1.5772 & 2 & $614+$ & & & & \\
\hline 1.5675 & 7 & $225+$ & & & 1.56 & 70 \\
\hline 1.5558 & 1 & 416 & & & & \\
\hline 1.5508 & 4 & 605 & & & & \\
\hline 1.5398 & 3 & 424 & & & & \\
\hline 1.5304 & 5 & 217 & & & & \\
\hline 1.5271 & 3 & $801+$ & & & 1.52 & 10 \\
\hline 1.5124 & 4 & 704 & & & & \\
\hline 1.5077 & 12 & $325+$ & & & & \\
\hline 1.4968 & 2 & 621 & & & & \\
\hline 1.4903 & 2 & 802 & & & 1.49 & 30 \\
\hline 1.4787 & 2 & 008 & & & & \\
\hline 1.4756 & 3 & 026 & & & & \\
\hline 1.4718 & 2 & 031 & & & & \\
\hline 1.4644 & 7 & $615+$ & & & & \\
\hline 1.4621 & 4 & 622 & & & & \\
\hline 1.4418 & 1 & $524+$ & & & 1.45 & 10 \\
\hline 1.4344 & 2 & $425+$ & & & & \\
\hline 1.4291 & 5 & $132+$ & & & & \\
\hline 1.4222 & 1 & 606 & & & & \\
\hline
\end{tabular}

Table 8: (continued). Calculated and PDF patterns (34-807 and 21-1408) for $\mathrm{U}_{2} \mathrm{Te}_{3}$. 


\begin{tabular}{|c|c|c|c|c|c|c|}
\hline d & $I^{r e l}$ & $\begin{array}{c}\text { Calculated } \\
\text { hk } \ell\end{array}$ & $\begin{array}{c}\text { PDF } 34-807 \\
\mathrm{~d}\end{array}$ & $I^{r e l}$ & $\begin{array}{c}\text { PDF 21-1408 } \\
\mathrm{d}\end{array}$ & $I^{r e l}$ \\
\hline 1.4132 & 4 & 812 & & & & \\
\hline 1.4093 & 10 & 623 & & & & \\
\hline 1.4058 & 16 & 417 & & & & \\
\hline 1.4011 & 11 & 232 & & & & \\
\hline 1.3943 & 5 & $118+$ & & & & \\
\hline 1.3884 & 5 & 033 & & & 1.39 & 10 \\
\hline 1.3796 & 2 & 133 & & & 1.37 & 20 \\
\hline 1.3682 & 1 & 218 & & & & \\
\hline 1.3659 & 1 & 804 & & & & \\
\hline 1.3579 & 4 & $332+$ & & & 1.356 & 10 \\
\hline 1.3547 & 4 & 616 & & & & \\
\hline 1.3460 & 2 & 715 & & & & \\
\hline 1.3442 & 2 & $722+$ & & & & \\
\hline 1.3364 & 2 & 430 & & & & \\
\hline 1.3336 & 3 & 902 & & & & \\
\hline 1.3308 & 4 & 426 & & & & \\
\hline 1.3280 & 5 & $431+$ & & & 1.324 & 30 \\
\hline 1.3148 & 9 & $227+$ & & & & \\
\hline 1.3058 & 5 & $814+$ & & & & \\
\hline 1.3029 & 8 & $723+$ & & & & \\
\hline 1.3004 & 4 & 911 & & & & \\
\hline
\end{tabular}

Table 8: (continued). Calculated and PDF patterns (34-807 and 21-1408) for $\mathrm{U}_{2} \mathrm{Te}_{3}$. 


\begin{tabular}{|c|c|c|c|c|c|c|}
\hline d & Irel & $\begin{array}{c}\text { Calculated } \\
\text { hk } \ell\end{array}$ & $\begin{array}{c}\text { PDF 34-807 } \\
\text { d }\end{array}$ & $\mathrm{I}^{\text {rel }}$ & $\begin{array}{c}\text { PDE 21-1408 } \\
\text { d }\end{array}$ & I $^{\text {rel }}$ \\
\hline 1.2962 & 3 & 234 & & & & \\
\hline 1.2932 & 2 & 903 & & & 1.291 & 40 \\
\hline 1.2775 & 4 & 912 & & & 1.278 & 10 \\
\hline 1.2723 & 4 & 625 & & & & \\
\hline 1.2679 & 3 & 508 & & & & \\
\hline 1.2606 & 7 & $019+$ & & & & \\
\hline 1.2593 & 7 & 716 & & & & \\
\hline 1.2568 & 6 & 035 & & & 1.255 & 10 \\
\hline 1.2508 & 4 & $724+$ & & & & \\
\hline 1.2423 & 3 & $904+$ & & & 1.244 & 20 \\
\hline 1.2396 & 4 & $815+$ & & & & \\
\hline 1.2316 & 3 & $028+$ & & & & \\
\hline 1.2254 & 2 & 1001 & & & & \\
\hline
\end{tabular}

Table 8: (continued). Calculated and PDF patterns (34-807 and 21-1408) for $\mathrm{U}_{2} \mathrm{Te}_{3}$. 


\begin{tabular}{|c|c|c|c|c|}
\hline Phase & Reference & a $(\AA)$ & b $(\AA)$ & c $(\AA)$ \\
\hline $\mathrm{U}_{3} \mathrm{Te}_{5}$ & Slovyanskikh 1977[28] & 7.987 & 8.728 & 13.046 \\
$\mathrm{U}_{3} \mathrm{Te}_{5}^{\prime}$ & Slovyanskikh $1277[28]$ & 7.99 & 8.738 & 12.88 \\
\hline
\end{tabular}

Table 9: Lattice parameters for the reported orthorhombic forms of $\mathrm{U}_{3} \mathrm{Te}_{5}$.

\section{$6 \mathrm{U}_{3} \mathrm{Te}_{5}\left(\mathrm{UTe}_{1.666}\right)$}

Slovyanskikh et al.[27] reported the existence of $\mathrm{U}_{3} \mathrm{Te}_{5}$ and their powder pattern was abstracted as PDF 21-1407. Again in 1977 Slovyanskikh et al.[28] confirmed the observation, after Suski and Reizner-Netter[31] had expressed doubts about its existence, and identified two types containing a bit less uranium than called for in the formula. The orthorhombic unit cells for the two types were given as shown in Table 9. The powder patterns for these two materials were abstracted as PDF 34-766 and 34-896.

The first report of Slovyanskikh et al.[27] was later corrected by Ellert, Sevast'yanov and Slovyanskikh[9] to actually be $\mathrm{U}_{7} \mathrm{Te}_{12}$. Thus, we have compared the deleted pattern PDF 21-1408 to the calculated one for $\mathrm{U}_{7} \mathrm{Te}_{12}$. The two patterns which remain for $\mathrm{U}_{3} \mathrm{Te}_{5}$ were determined using a DebyeScherrer camera and only give the dozen or so most intense lines to a very low degree of accuracy. It is clear that a better standard is needed. However, in the absence of a structural model, no calculated pattern can be produced. In order to use the Crystal Data database to try to find isomorphous structure 
types, more precise cell information will be required.

\section{$7 \quad \mathrm{U}_{7} \mathrm{Te}_{12}\left(\mathrm{UTe}_{1.714}\right)$}

Breeze et al.[3] first reported a phase of this stoichiometry and their pattern appears as PDF 24-1368. Breeze and Brett[4] determined the crystal structure of this phase as being isostructural with $\mathrm{Th}_{7} \mathrm{~S}_{12}[35]$. Using this model we have calculated the pattern for $\mathrm{U}_{7} \mathrm{Te}_{12}$. We have compared this pattern in Table 10 to that reported by Breeze et al.[3] and to the pattern (PDF 21-14(17) reported by Slovyanskikh et al.[27] initially claimed to be $\mathrm{U}_{3} \mathrm{Te}_{5}$ but later claimed to be $\mathrm{U}_{7} \mathrm{Te}_{12}[9]$. It is interesting to note that even though all of the experimental data was collected with low resolution cameras, the disagreement with the proposed model is worse that it should be. A carefully measured experimental pattern of this phase and a Rietveld analysis will be required before anything more certain can be said about its existence or structure. 


\begin{tabular}{|c|c|c|c|c|c|c|}
\hline$d$ & $I^{r e l}$ & $\begin{array}{c}\text { Calculated } \\
\text { hk } \ell\end{array}$ & $\begin{array}{c}\text { PDF 24-1368 } \\
\mathrm{d}\end{array}$ & $\mathrm{I}^{\mathrm{rel}}$ & $\begin{array}{c}\text { PDF 21-1407 } \\
\mathrm{d}\end{array}$ & $\mathrm{I}^{r e l}$ \\
\hline 10.660 & 100 & 100 & & & & \\
\hline 6.155 & 5 & 110 & & & & \\
\hline 5.330 & 5 & 200 & & & & \\
\hline 4.029 & 9 & 210 & 4.01 & 50 & & \\
\hline 3.941 & 1 & 101 & 3.95 & 20 & & \\
\hline 3.553 & 3 & 300 & & & & \\
\hline 3.493 & 1 & 111 & & & & \\
\hline 3.319 & 27 & 201 & 3.31 & 30 & & \\
\hline 3.077 & 4 & 220 & 3.08 & 20 & & \\
\hline 2.957 & 23 & $\begin{array}{lll}31 & 0\end{array}$ & & & & \\
\hline 2.921 & 47 & 211 & 2.91 & 100 & 2.91 & 100 \\
\hline 2.724 & 2 & $\begin{array}{lll}301 & 1\end{array}$ & 2.715 & 90 & 2.72 & 75 \\
\hline & & & 2.658 & 30 & & \\
\hline 2.491 & 2 & 221 & 2.485 & 50 & 2.49 & 35 \\
\hline 2.446 & 9 & $320+$ & 2.421 & 50 & 2.43 & 35 \\
\hline 2.326 & 3 & $140+$ & 2.326 & 90 & 2.31 & 100 \\
\hline 2.257 & 2 & 401 & 2.256 & 20 & & \\
\hline 2.121 & $1^{n}$ & 002 & 2.118 & 50 & 2.12 & 50 \\
\hline 2.080 & 3 & 102 & 2.010 & 40 & & \\
\hline 2.040 & 5 & $141+$ & & & & \\
\hline 2.015 & 1 & 240 & & & 2.02 & 25 \\
\hline 2.005 & 1 & 112 & & & & \\
\hline
\end{tabular}

Table 10: Calculated and PDF patterns (24-1368 and 21-1407) for $\mathrm{U}_{7} \mathrm{Te}_{12}$. 


\begin{tabular}{|c|c|c|c|c|c|c|}
\hline$d$ & $I^{r e l}$ & $\begin{array}{c}\text { Calculated } \\
\text { hk } \ell\end{array}$ & $\begin{array}{c}\text { PDF 24-1368 } \\
\text { d }\end{array}$ & $I^{r e l}$ & $\begin{array}{c}\text { PDF 21-1407 } \\
\text { d }\end{array}$ & Irel \\
\hline 1.9707 & 1 & 202 & & & & \\
\hline 1.9146 & 1 & 150 & & & & \\
\hline 1.9049 & 3 & 501 & & & & \\
\hline 1.8768 & 2 & 212 & 1.875 & 30 & 1.87 & 15 \\
\hline 1.8469 & 2 & 331 & & & & \\
\hline 1.8197 & 5 & $241+$ & & & & \\
\hline 1.7451 & 8 & $151+$ & 1.744 & 20 & & \\
\hline 1.7234 & 8 & $312+$ & & & & \\
\hline 1.7069 & 2 & 520 & 1.705 & 30 & 1.70 & 35 \\
\hline & & & 1.656 & 20 & 1.66 & 5 \\
\hline 1.6197 & 2 & 341 & 1.619 & 50 & 1.61 & 60 \\
\hline 1.6023 & 4 & $322+$ & & & & \\
\hline 1.5835 & 12 & 521 & 1.582 & 60 & 1.58 & 75 \\
\hline 1.5673 & 2 & $142+$ & 1.566 & 60 & 1.56 & 60 \\
\hline 1.5386 & 1 & 440 & & & & \\
\hline 1.5228 & 2 & 700 & 1.520 & 40 & 1.52 & 15 \\
\hline 1.5180 & 2 & 611 & & & & \\
\hline 1.4607 & 1 & 242 & 1.460 & 40 & 1.46 & 5 \\
\hline 1.4212 & 1 & 152 & & & 1.43 & 15 \\
\hline 1.4119 & 1 & 170 & & & & \\
\hline 1.3649 & 5 & $540+$ & & & 1.375 & 15 \\
\hline 1.3397 & 1 & 171 & & & 1.338 & 100 \\
\hline
\end{tabular}

Table 10: (continued). Calculated and PDF patierns (24-1368 and 21-1407) for $\mathrm{U}_{7} \mathrm{Te}_{12}$. 


\begin{tabular}{|c|c|c|c|c|c|c|}
\hline d & $I^{r e l}$ & $\begin{array}{c}\text { Calculated } \\
\text { hk } \ell\end{array}$ & $\begin{array}{c}\text { PDF 24-1368 } \\
d\end{array}$ & $\mathrm{I}^{\mathrm{rel}}$ & $\begin{array}{c}\text { PDF 21-1407 } \\
\mathrm{d}\end{array}$ & $\mathrm{I}^{\mathrm{rel}}$ \\
\hline 1.3342 & 4 & 213 & & & & \\
\hline 1.3325 & 4 & 800 & & & & \\
\hline \multirow[t]{2}{*}{1.3298} & 4 & 522 & & & 1.316 & 35 \\
\hline & & & & & 1.295 & 25 \\
\hline 1.2450 & 2 & $721+$ & & & 1.246 & 5 \\
\hline 1.2370 & 2 & 702 & & & 1.237 & 5 \\
\hline 1.2309 & 1 & 550 & & & & \\
\hline 1.2083 & 1 & 143 & & & & \\
\hline 1.1969 & 1 & 181 & & & 1.197 & 35 \\
\hline 1.1753 & 1 & $172+$ & & & & \\
\hline 1.1574 & 1 & 243 & & & 1.161 & 15 \\
\hline 1.1541 & 3 & 731 & & & & \\
\hline 1.1478 & 4 & $542+$ & & & 1.149 & 15 \\
\hline 1.1374 & 1 & 153 & & & 1.135 & 5 \\
\hline 1.1283 & 3 & 802 & & & 1.116 & 15 \\
\hline 1.1217 & 1 & 821 & & & 1.102 & 75 \\
\hline 1.0889 & 3 & 523 & & & 1.089 & 100 \\
\hline 1.0646 & 1 & 552 & & & 1.065 & 5 \\
\hline \multirow[t]{4}{*}{1.0605} & 1 & 004 & & & 1.058 & 5 \\
\hline & & & & & 1.049 & 25 \\
\hline & & & & & 1.044 & 15 \\
\hline & & & & & 1.036 & 5 \\
\hline
\end{tabular}

Table 10: (continued). Calculated and PDF patterns (24-1368 and 21-1407) for $\mathrm{U}_{7} \mathrm{Te}_{12}$. 


\begin{tabular}{|c|c|c|c|c|c|c|}
\hline$d$ & $1^{r e l}$ & $\begin{array}{c}\text { Calculated } \\
\text { hk } \ell\end{array}$ & $\begin{array}{c}\text { PDF 24-1368 } \\
\mathrm{d}\end{array}$ & $I^{r e l}$ & $\begin{array}{c}\text { PDF 21-1407 } \\
\text { d }\end{array}$ & Irel \\
\hline \multirow[t]{3}{*}{1.0338} & 1 & 1001 & & & 1.032 & 25 \\
\hline & & & & & 1.019 & 100 \\
\hline & & & & & 1.000 & 75 \\
\hline \multirow[t]{2}{*}{0.9982} & 1 & 314 & & & 0.998 & 85 \\
\hline & & & & & 0.996 & 25 \\
\hline 0.9927 & 1 & $751+$ & & & 0.991 & 25 \\
\hline 0.9855 & 2 & 390 & & & & \\
\hline \multirow[t]{2}{*}{0.9842} & 1 & 1011 & & & 0.983 & 75 \\
\hline & & & & & 0.980 & 15 \\
\hline 0.9730 & 1 & 324 & & & 0.974 & 25 \\
\hline 0.9579 & 1 & 723 & & & & \\
\hline 0.9243 & 1 & $1110+$ & & & & \\
\hline 0.9232 & 1 & 671 & & & & \\
\hline 0.9146 & 1 & 733 & & & & \\
\hline 0.9031 & 1 & 1111 & & & & \\
\hline 0.9008 & 1 & 524 & & & & \\
\hline 0.8983 & 1 & 823 & & & & \\
\hline 0.8937 & 3 & $392+$ & & & & \\
\hline 0.8703 & 1 & 704 & & & & \\
\hline 0.8499 & 1 & 591 & & & & \\
\hline 0.8474 & 2 & $1112+$ & & & & \\
\hline 0.8374 & 2 & $454+$ & & & & \\
\hline
\end{tabular}

Table 10: (continued). Calculated and PDF patterns (24-1368 and 21-1407) for $\mathrm{U}_{7} \mathrm{Te}_{12}$. 


\section{$8 \mathrm{UTe}_{1.78}$}

\subsection{UTe $\mathrm{UT}_{1.78}$-Orthorhombic}

The story in this section of the phase diagram gets particularly complicated. All phases reported in this vicinity appear to be defect structures of $\mathrm{UTe}_{2}$. Whether any of these phases actually exist at all is problematical. Breeze et al.[3] report an orthorhombic structure which extends from $\mathrm{UTe}_{2}$ to $\mathrm{UTe}_{1.78 \text {. }}$ There are many confirming reports of this structure with the $\mathrm{UTe}_{2}$ stoichiometry but only a few reporting uranium deficient compositions[27]. The powder diffraction file has pattern 21-1404 reported as $\mathrm{U}_{4} \mathrm{Te}_{7}$ (i.e. $\mathrm{UTe}_{1.75}$ ) from Slovyanskikh et al.[27]. This is the only published pattern in this range of stoichiometry that could be orthorhombic. Our calculated pattern shown in Table 11 is based on the $\mathrm{UTe}_{2}$ structure[16] and the lattice parameter of Breeze et al.[3] shown in Table 1. The vacancies are placed equally on the two tellurium sites for lack of a better assumption. The PDF pattern 21-1404 has been corrected for some minor errors from the original paper[27]. 


\begin{tabular}{|c|c|c|c|c|}
\hline d & $\mathrm{I}^{\text {rel }}$ & $\begin{array}{c}\text { Calculated } \\
\text { hke }\end{array}$ & $\begin{array}{l}\text { PDF 21-1404 } \\
\text { d }\end{array}$ & Irel \\
\hline 5.608 & 38 & 011 & 5.62 & 40 \\
\hline 3.988 & 5 & 101 & & \\
\hline 3.705 & 8 & 013 & 3.76 & 50 \\
\hline 3.490 & 2 & 004 & & \\
\hline \multirow[t]{2}{*}{3.442} & 9 & 110 & & \\
\hline & & & 3.25 & 10 \\
\hline 3.102 & 100 & 103 & 3.10 & 100 \\
\hline 3.062 & 19 & 020 & & \\
\hline \multirow[t]{2}{*}{2.804} & 28 & 022 & 2.81 & 100 \\
\hline & & & 2.75 & 60 \\
\hline \multirow[t]{2}{*}{2.540} & 17 & 015 & 2.55 & 60 \\
\hline & & & 2.51 & 10 \\
\hline 2.451 & 44 & 114 & 2.46 & 40 \\
\hline 2.429 & 57 & 121 & 2.44 & 40 \\
\hline 2.326 & 8 & 006 & & \\
\hline 2.318 & 7 & 105 & 2.31 & 10 \\
\hline 2.302 & 22 & 024 & 2.22 & 70 \\
\hline 2.179 & 11 & 123 & 2.19 & 20 \\
\hline 2.081 & 19 & 200 & 2.08 & 5 \\
\hline 2.020 & 2 & 031 & 2.02 & 10 \\
\hline 1.9510 & 4 & 211 & & \\
\hline
\end{tabular}

Table 11: Calculated pattern for UTe1.78 (left) and the observed (21-1404) for the claimed $\mathrm{U}_{4} \mathrm{Te}_{7}$. 


\begin{tabular}{|c|c|c|c|c|}
\hline d & $I^{r e l}$ & $\begin{array}{c}\text { Calculated } \\
\text { hk } \ell\end{array}$ & $\begin{array}{l}\text { PDF 21-1404 } \\
\text { d }\end{array}$ & I $^{\text {el }}$ \\
\hline 1.9274 & 1 & 116 & 1.93 & 10 \\
\hline 1.8960 & 13 & 017 & 1.91 & 80 \\
\hline 1.8693 & 1 & 033 & 1.87 & 80 \\
\hline 1.8484 & 4 & 125 & & \\
\hline 1.8328 & 2 & 130 & & \\
\hline 1.8144 & 2 & 213 & & \\
\hline 1.7727 & 1 & 132 & & \\
\hline 1.7448 & 3 & 008 & 1.74 & 5 \\
\hline 1.7211 & 5 & 220 & 1.72 & 5 \\
\hline & & & 1.70 & 70 \\
\hline 1.6711 & 10 & 222 & 1.67 & 10 \\
\hline 1.6478 & 4 & 035 & 1.65 & 60 \\
\hline 1.6226 & 10 & 134 & 1.62 & 60 \\
\hline 1.6098 & 7 & 215 & 1.61 & 5 \\
\hline 1.5563 & 11 & 118 & 1.56 & 50 \\
\hline 1.5506 & 13 & $127+$ & & \\
\hline 1.5436 & 12 & 224 & 1.53 & 5 \\
\hline 1.5310 & 7 & 040 & 1.50 & 40 \\
\hline 1.4494 & 1 & 231 & & \\
\hline 1.4264 & 4 & 037 & 1.43 & 40 \\
\hline 1.4015 & 8 & 217 & 1.40 & 40 \\
\hline 1.3907 & 1 & 233 & & \\
\hline
\end{tabular}

Table 11: (continued). Calculated pattern for UTe $\mathrm{U}_{.78}$ (left) and the observed (21-1404) for the claimed $\mathrm{U}_{4}$ 'le 7. 


\begin{tabular}{|c|c|c|c|c|}
\hline d & $\mathrm{I}^{r e l}$ & $\begin{array}{c}\text { Calculated } \\
\text { like }\end{array}$ & $\begin{array}{l}\text { PDF 21-1404 } \\
\text { d }\end{array}$ & $\mathrm{I}^{\text {rel }}$ \\
\hline 1.3729 & 12 & 143 & 1.372 & 100 \\
\hline 1.3370 & 2 & 208 & & \\
\hline 1.3295 & 6 & 303 & 1.324 & 20 \\
\hline 1.3129 & 3 & 129 & 1.316 & 10 \\
\hline 1.2935 & 5 & 1110 & 1.295 & 70 \\
\hline 1.2918 & 4 & 235 & & \\
\hline 1.2789 & 2 & $046+$ & 1.281 & 30 \\
\hline 1.2701 & 1 & 0210 & & \\
\hline 1.2637 & 5 & 138 & & \\
\hline 1.2615 & 6 & 314 & 1.262 & 30 \\
\hline 1.2585 & 8 & 321 & & \\
\hline 1.2425 & 2 & 0111 & 1.246 & 30 \\
\hline 1.2332 & 5 & 240 & 1.231 & 30 \\
\hline 1.2195 & 2 & 323 & & \\
\hline \multirow[t]{2}{*}{1.2138} & 3 & 1011 & 1.211 & 20 \\
\hline & & & 1.197 & 10 \\
\hline 1.1766 & 4 & 237 & 1.176 & 50 \\
\hline \multirow[t]{3}{*}{1.1508} & 2 & $048+$ & 1.150 & 10 \\
\hline & & & 1.142 & 50 \\
\hline & & & 1.128 & 10 \\
\hline 1.1216 & 1 & $05 \%$ & 1.121 & 10 \\
\hline 1.1135 & 3 & 154 & 1.113 & 80 \\
\hline
\end{tabular}

Table 11: (continued). Calculated pattern for UTe $\mathrm{U}_{1.78}$ (left) and the observed (21-1404) for the claimed $\mathrm{U}_{4} \mathrm{Te}_{7}$. 


\begin{tabular}{|c|c|c|c|c|}
\hline d & $\mathrm{I}^{\mathrm{rel}}$ & $\begin{array}{c}\text { Calculated } \\
\text { hk } \ell\end{array}$ & $\begin{array}{l}\text { PDF 21-1404 } \\
\text { d }\end{array}$ & $\mathrm{I}^{\mathrm{rel}}$ \\
\hline 1.1104 & 3 & 1310 & & \\
\hline 1.0900 & 4 & $334+$ & & \\
\hline 1.0874 & 4 & 0212 & 1.087 & 80 \\
\hline 1.0841 & 2 & 2210 & & \\
\hline 1.0777 & 1 & 0311 & 1.077 & 10 \\
\hline 1.0692 & 3 & 318 & & \\
\hline 1.0668 & 4 & $2111+$ & $\begin{array}{l}1.066 \\
1.059\end{array}$ & $\begin{array}{l}50 \\
20\end{array}$ \\
\hline 1.0436 & 2 & 057 & 1.044 & 30 \\
\hline 1.0405 & 2 & $400+$ & 1.032 & 70 \\
\hline 1.0099 & 1 & 0.62 & 1.020 & 5 \\
\hline 1.0071 & 2 & 248 & 1.011 & 5 \\
\hline 1.0038 & 4 & 343 & $1.0 ? ?$ & 60 \\
\hline 0.9970 & 1 & 0014 & 0.999 & 80 \\
\hline 0.9888 & 3 & 161 & 0.988 & 30 \\
\hline 0.9873 & 2 & 255 & & \\
\hline 0.9852 & 1 & 420 & 0.981 & 20 \\
\hline 0.9797 & 2 & $329+$ & 0.979 & 10 \\
\hline 0.9755 & 2 & 422 & 0.975 & 30 \\
\hline 0.9746 & 2 & 158 & & \\
\hline 0.9715 & 2 & 3110 & & \\
\hline
\end{tabular}

Table 11: (continued). Calculated pattern for $\mathrm{UTe}_{\mathbf{1 . 7 8}}$ (left) and the observed (21-1404) for the claimed $\mathrm{U}_{4} \mathrm{Ter}$. 


\begin{tabular}{|c|c|c|c|c|}
\hline d & $\mathrm{I}^{\text {rel }}$ & $\begin{array}{c}\text { Calculated } \\
\text { hke }\end{array}$ & $\begin{array}{l}\text { PDF 21-1404 } \\
\text { d }\end{array}$ & $I^{\text {rel }}$ \\
\hline 0.9695 & 1 & 163 & & \\
\hline 0.9637 & 4 & $2212+$ & & \\
\hline 0.9587 & 2 & 338 & & \\
\hline 0.9570 & 2 & 2311 & & \\
\hline 0.9511 & 3 & 1411 & & \\
\hline 0.9498 & 1 & 406 & & \\
\hline 0.9481 & 3 & 424 & & \\
\hline 0.9363 & 1 & 3011 & & \\
\hline 0.9341 & 1 & 165 & & \\
\hline 0.9329 & 2 & 257 & & \\
\hline 0.9164 & 1 & 260 & & \\
\hline 0.9122 & 2 & 417 & & \\
\hline 0.9103 & 1 & 352 & & \\
\hline 0.9086 & 2 & $262+$ & & \\
\hline 0.8991 & 3 & $2014+$ & & \\
\hline 0.8936 & 1 & 408 & & \\
\hline 0.8880 & 2 & $3: 4+$ & & \\
\hline 08863 & 4 & $264+$ & & \\
\hline 0.8813 & 1 & $0 \leq 11$ & & \\
\hline 0.8798 & 1 & 435 & & \\
\hline 0.8724 & 1 & 0016 & & \\
\hline
\end{tabular}

Table 11: (continued). Calculated pattern for $\mathrm{UTe}_{1.78}$ (left) and the observed (21-1404) for the claimed $\mathrm{U}_{4} \mathrm{Te}_{7}$. 


\begin{tabular}{|r|r|r|l|l|}
\hline $\mathrm{d}$ & $\mathrm{l}$ rel & $\begin{array}{c}\text { Calculated } \\
\text { hlk } \ell\end{array}$ & $\mathrm{d}$ PDF 21-1404 & rel \\
\hline 0.8706 & 5 & 1215 & & \\
0.8606 & 3 & $440+$ & & \\
0.8462 & 1 & 2412 & & \\
0.8406 & 2 & 437 & & \\
0.8355 & 2 & $0414+$ & & \\
0.8315 & 1 & 174 & & \\
0.8207 & 2 & 361 & & \\
0.8194 & 2 & 503 & & \\
0.8169 & 1 & 3312 & & \\
0.8125 & 2 & 358 & & \\
0.8115 & 1 & 2511 & & \\
0.8096 & 1 & 363 & & \\
0.8071 & 1 & 446 & & \\
0.8055 & 1 & 1017 & & \\
0.8051 & 1 & $271+$ & & \\
0.8045 & 1 & 2016 & & \\
0.8035 & 1 & 176 & & \\
0.8027 & 2 & $514+$ & & \\
0.8019 & 2 & 521 & & \\
0.8011 & 2 & 077 & & \\
0.7988 & 2 & 3411 & & \\
\hline
\end{tabular}

Table 11: (continued). Calculated pattern for UTe $\mathrm{T}_{1.78}$ (left) and the observed (21-1404) for the claimed $\mathrm{U}_{4} \mathrm{Te}_{7}$. 


\section{2 $\mathrm{UTe}_{1.78}$-Tetragonal}

There are a number of reports of a tetragonal $\mathrm{UTe}_{2}$ that will be discussed below. Klein-Haneveld and Jellinek[15, 16] reported a tetragonal UTe ${ }_{1.77^{1}}$ to be tetragonal with the $\mathrm{ThAs}_{2}$ structure and a cell of $\mathrm{a}=4.243 \AA$ and $c=8.946 \AA$. In their second report they note that this phase can only be stabilized in the presence of germanium. It is probable that this phase was UTeGe. They never again claimed it to be a uranium telluride. Our conclusion is that the reports of tetragonal $\mathrm{UTe}_{1.77}$ are so tenuous that a calculated pattern based on a defect $\mathrm{ThAs}_{2}$ structure is not justified.

\section{$9 \mathrm{UTe}_{2}$}

Three forms of $\mathrm{UTe}_{2}$ have been claimed to exist: orthorhombic, tetragonal and cubic phases.

\section{1 $\mathrm{UTe}_{2}$-Orthorhombic}

Klein-Haneveld and Jell nek[16] first reported and unambiguously established the crystal structure of orthorhombic U'Te2. The results of the structure analysis are given in Tables 1 and 3 . This orthorhombic form has since been reported by numerous authors and recently confirmed by $\mathrm{Ri}$ etveld analysis[2]. The editors of the Powder Diffraction File have deleted

\footnotetext{
${ }^{1}$ This was erroneously initially reported to be $\mathrm{UT}_{1,87}[15]$ and later corrected to be $\mathrm{UTe}_{1.77}[16]$.
} 
the very poor pattern (21-1405)[27] in preference to the still rather poor, but better, pattern 24-1370 of Klein-Haneveld and Jellinek[16]. Boehme et al.[2] have produced a high quality pattern in conjunction with the current study. Table 12 shows the calculated pattern along with the current PDF pattern and the new one of Boehme et al.[2].

This powder pattern is a substantial improvement over PDF 24-1370 in that it corrects a number of problems. It is also considerably better that PDF 21-1405 in that a number of major errors have been corrected. 


\begin{tabular}{|c|c|c|c|c|c|c|}
\hline d & $\mathrm{I}^{\mathrm{rel}}$ & $\begin{array}{c}\text { Calculated } \\
\text { hk } \ell\end{array}$ & $\begin{array}{c}\text { Boehme et al.[2] } \\
\text { d }\end{array}$ & $I^{r e l}$ & $\begin{array}{c}\text { PDF 24-1370 } \\
\text { d }\end{array}$ & $I^{r e l}$ \\
\hline 6.982 & 0 & 002 & & & 6.98 & $<1$ \\
\hline 5.611 & 28 & 011 & 5.612 & 30 & 5.61 & $<1$ \\
\hline 3.988 & 3 & 101 & 3.987 & 12 & 3.99 & $<1$ \\
\hline 3.707 & 6 & 013 & 3.708 & 17 & 3.71 & $<1$ \\
\hline 3.491 & 1 & 004 & & & 3.49 & $<1$ \\
\hline 3.443 & 6 & 110 & 3.442 & 22 & 3.44 & $<1$ \\
\hline 3.103 & 100 & 103 & 3.104 & 100 & 3.10 & 100 \\
\hline 3.088 & 7 & 112 & & & 3.09 & 100 \\
\hline 3.064 & 14 & 020 & 3.066 & 38 & 3.06 & 20 \\
\hline 2.806 & 31 & 022 & 2.807 & 48 & 2.806 & 35 \\
\hline 2.541 & 17 & 015 & 2.542 & 27 & 2.541 & 20 \\
\hline 2.451 & 42 & 114 & 2.452 & 49 & 2.451 & 50 \\
\hline 2.430 & 58 & 121 & 2.430 & 54 & 2.430 & 75 \\
\hline 2.328 & 7 & 006 & 2.327 & 15 & 2.327 & 10 \\
\hline 2.319 & 3 & 105 & & & 2.319 & 10 \\
\hline 2.303 & 22 & 024 & 3.304 & 31 & 2.303 & 30 \\
\hline 2.180 & 10 & 123 & 2.180 & 17 & 2.180 & 10 \\
\hline 2.081 & 21 & 200 & 2.081 & 20 & 2.081 & 20 \\
\hline 2.021 & 2 & 031 & & & 2.021 & 5 \\
\hline 1.9942 & 0 & 202 & 1.9969 & 36 & 1.994 & $<1$ \\
\hline 1.9510 & 3 & 211 & 1.9513 & 15 & 1.951 & 5 \\
\hline 1.9282 & 1 & 116 & 1.9203 & 24 & 1.928 & $<1$ \\
\hline
\end{tabular}

Table 12: Calculated and observed patterns (Boehme et al. and 24-1370) for orthorhombic UTe. 


\begin{tabular}{|c|c|c|c|c|c|c|}
\hline $\mathrm{d}$ & $\mathrm{I}^{\mathrm{rel}}$ & $\begin{array}{c}\text { Calculated } \\
\text { hk } \ell\end{array}$ & $\begin{array}{c}\text { Boehme et al.[2] } \\
\text { d }\end{array}$ & $\mathrm{I}^{\mathrm{rel}}$ & $\begin{array}{c}\text { PDF 24-1370 } \\
\mathrm{d} \\
\end{array}$ & $I^{r e l}$ \\
\hline 1.8970 & 12 & 017 & 1.8968 & 24 & 1.987 & 15 \\
\hline 1.8704 & 1 & 033 & 1.8719 & 14 & 1.870 & 2 \\
\hline 1.8534 & 0 & 026 & & & 1.853 & 10 \\
\hline 1.8491 & 6 & 125 & 1.8490 & 16 & 1.849 & 10 \\
\hline 1.8336 & 1 & 130 & & & 1.834 & 2 \\
\hline 1.8145 & 1 & 213 & & & 1.814 & 2 \\
\hline 1.7990 & $<1$ & 107 & & & 1.799 & $<1$ \\
\hline 1.7874 & $<1$ & 204 & & & 1.787 & $<1$ \\
\hline 1.7735 & 1 & 132 & & & 1.773 & 2 \\
\hline 1.7456 & 3 & 008 & & & 1.746 & 2 \\
\hline 1.7214 & 5 & 220 & & & 1.721 & 5 \\
\hline 1.6713 & 12 & 222 & 1.6716 & 16 & 1.671 & 20 \\
\hline 1.6487 & 4 & 035 & 1.6489 & 16 & 1.648 & 5 \\
\hline 1.6233 & 11 & 134 & 1.6237 & 22 & 1.623 & 20 \\
\hline 1.6100 & 7 & 215 & 1.6097 & 15 & 1.610 & 15 \\
\hline 1.5569 & 11 & 118 & 1.5567 & 21 & 1.557 & 50 \\
\hline 1.5513 & 7 & $127+$ & 1.5519 & 19 & 1.551 & 50 \\
\hline 1.5439 & 11 & 224 & 1.5435 & 15 & 1.544 & 50 \\
\hline 1.5319 & 7 & 040 & 1.5323 & 15 & 1.532 & 10 \\
\hline 1.5167 & 0 & 028 & & & 1.517 & $<1$ \\
\hline 1.5042 & 0 & 019 & & & 1.504 & $<1$ \\
\hline 1.4963 & 0 & 042 & & & 1.496 & $<1$ \\
\hline
\end{tabular}

Table 12: (continued). Calculated and observed patterns (Boehme et al. and 24-1370) for orthorhombic $\mathrm{UTe}_{2}$. 


\begin{tabular}{|c|c|c|c|c|c|c|}
\hline $\mathrm{d}$ & $\mathrm{I}^{\text {rel }}$ & $\begin{array}{c}\text { Calculated } \\
\text { hk } \ell\end{array}$ & $\begin{array}{c}\text { Boehme et al.[2] } \\
\text { d }\end{array}$ & $\mathrm{I}^{\text {rel }}$ & $\begin{array}{c}P[>24-1370 \\
d\end{array}$ & $I^{\text {rel }}$ \\
\hline 1.4539 & 0 & 109 & & & 1.454 & 2 \\
\hline 1.4498 & 1 & 231 & & & 1.450 & 2 \\
\hline 1.4403 & $<1$ & 136 & & & 1.440 & $<1$ \\
\hline 1.4300 & $<1$ & 141 & & & 1.430 & 10 \\
\hline 1.4272 & 5 & 037 & 1.4271 & 11 & 1.427 & 10 \\
\hline 1.4208 & $<1$ & 044 & & & 1.403 & 15 \\
\hline 1.4019 & 8 & 217 & 1.4016 & 11 & 1.402 & 15 \\
\hline 1.3965 & $<1$ & 0010 & & & 1.397 & 15 \\
\hline 1.3910 & $<1$ & 233 & & & 1.391 & 2 \\
\hline 1.3840 & 0 & 226 & & & 1.384 & $<1$ \\
\hline 1.3804 & 0 & $\begin{array}{lll}3 & 0 & 1\end{array}$ & & & 1.380 & $<1$ \\
\hline 1.3736 & 12 & 143 & 1.3740 & 25 & 1.374 & 25 \\
\hline 1.3530 & $<1$ & 310 & 1.3545 & 7 & 1.353 & $<1$ \\
\hline 1.3374 & 2 & 208 & & & 1.337 & 5 \\
\hline 1.3295 & 6 & 303 & 1.3288 & 8 & 1.329 & 10 \\
\hline 1.3283 & $<1$ & 312 & & & 1.328 & 10 \\
\hline 1.3135 & 3 & $: 29$ & 1.3133 & 8 & 1.314 & 5 \\
\hline 1.2941 & 4 & 1110 & & & 1.294 & 15 \\
\hline 1.2923 & 1 & 235 & 1.2922 & 11 & 1.292 & 15 \\
\hline 1.2796 & 2 & () $46+$ & 1.2796 & 9 & 1.280 & 5 \\
\hline 1.2782 & $<1$ & 145 & & & 1.278 & 5 \\
\hline 1.2707 & 1 & 02.10 & & & 1.271 & 2 \\
\hline
\end{tabular}

Table 12: (continued). Calculated and observed patterns (Boehme et al. and 24-1370) for orthorhombic (TTro. 


\begin{tabular}{|c|c|c|c|c|c|c|}
\hline$d$ & $\mathrm{I}^{\mathrm{rel}}$ & $\begin{array}{c}\text { Calculated } \\
\text { hk } \ell\end{array}$ & $\begin{array}{c}\text { Boehme et al.[2] } \\
\text { d }\end{array}$ & $\mathrm{I}^{\mathrm{rel}}$ & $\begin{array}{c}\text { PDF 24-1370 } \\
\text { d }\end{array}$ & $\mathrm{I}^{\text {rel }}$ \\
\hline 1.2643 & 5 & 138 & 1.2643 & 12 & 1.264 & 30 \\
\hline 1.2616 & 4 & 314 & 1.2611 & 12 & 1.262 & 30 \\
\hline 1.2586 & 6 & 321 & 1.2583 & 10 & 1.259 & 30 \\
\hline 1.2431 & 2 & 0111 & 1.2429 & 11 & 1.243 & 2 \\
\hline 1.2424 & $<1$ & 305 & & & 1.242 & 2 \\
\hline \multirow[t]{2}{*}{1.2336} & 6 & 240 & 1.2336 & 14 & 1.236 & 10 \\
\hline & & 240 & & & 1.234 & 10 \\
\hline 1.2257 & 0 & 228 & 1.2255 & 2 & 1.226 & $<1$ \\
\hline 1.2208 & $<1$ & 051 & & & 1.221 & 10 \\
\hline 1.2196 & 1 & 323 & 1.2193 & 2 & 1.220 & 10 \\
\hline 1.2148 & 0 & 242 & & & 1.215 & 10 \\
\hline 1.2143 & 2 & 1011 & 1.2139 & 9 & 1.214 & 10 \\
\hline 1.1851 & $<1$ & 053 & 1.1854 & $<1$ & 1.185 & $<1$ \\
\hline 1.1770 & 4 & 237 & 1.1772 & 9 & 1.77 & 10 \\
\hline 1.1756 & $<1$ & 150 & & & 1.1760 & 10 \\
\hline 1.1697 & $<1$ & 316 & & & 1.170 & 2 \\
\hline 1.1660 & 0 & 147 & & & 1.166 & 2 \\
\hline 1.1637 & $<1$ & 0012 & & & 1.164 & 2 \\
\hline 1.1632 & $<1$ & 244 & & & 1.1630 & 2 \\
\hline \multirow[t]{2}{*}{1.1596} & 1 & $2010+$ & $1 / 1593$ & 1 & 1.160 & 2 \\
\hline & & $2010+$ & & & 1.159 & 2 \\
\hline
\end{tabular}

Table 12: (continued). Calculated and observed patterns (Boehme et al. and 24-1370) for orthornombic $\mathrm{UTe}_{2}$. 


\begin{tabular}{|c|c|c|c|c|c|c|}
\hline $\mathrm{d}$ & $\mathrm{I}^{\mathrm{rel}}$ & $\begin{array}{c}\text { Calculated } \\
\text { hk } \ell\end{array}$ & $\begin{array}{c}\text { Boehme et al.[2] } \\
\text { d }\end{array}$ & Irel $^{\text {rel }}$ & $\begin{array}{c}\text { PDF 24-1370 } \\
\text { d }\end{array}$ & $I^{r e l}$ \\
\hline 1.1514 & 2 & 0484 & 1.1514 & 7 & & \\
\hline 1.1476 & $<1$ & 330 & & & & \\
\hline 1.1141 & 2 & 154 & 1.1141 & 8 & & \\
\hline 1.1110 & 3 & 1310 & 1.1085 & 13 & & \\
\hline 1.0902 & 4 & $334+$ & & & & \\
\hline 1.0879 & 4 & 0212 & 1.0878 & 9 & & \\
\hline 1.0845 & $<1$ & 2210 & & & & \\
\hline 1.0782 & 1 & 0311 & & & & \\
\hline 1.0694 & 3 & 318 & & & & \\
\hline 1.0672 & 2 & $2111+$ & & & & \\
\hline 1.0624 & 0 & 239 & & & & \\
\hline 1.0442 & 2 & 057 & 1.0450 & 9 & & \\
\hline 1.0404 & 2 & $400+$ & 1.0422 & 7 & & \\
\hline 1.0342 & 0 & 309 & & & & \\
\hline 1.0105 & 1 & 062 & & & & \\
\hline 1.0075 & 2 & 248 & & & & \\
\hline 1.0041 & 5 & 343 & & & & \\
\hline 1.0017 & $<1$ & 413 & & & & \\
\hline 0.9975 & 1 & 0014 & & & & \\
\hline 0.9894 & 3 & 161 & 0.9895 & 10 & & \\
\hline 0.9877 & 2 & 255 & 0.9872 & 7 & & \\
\hline 0.9852 & $<1$ & 420 & & & & \\
\hline
\end{tabular}

Table 12: (continued). Calculated and observad patterns (Boehme et al. and 24-1370) for orthorhombic UTe. 


\begin{tabular}{|c|c|c|c|c|c|c|}
\hline d & $\mathrm{I}^{\text {rel }}$ & $\begin{array}{c}\text { Calculated } \\
\text { hk } \ell\end{array}$ & $\begin{array}{c}\text { Boehme et al.[2] } \\
\text { d }\end{array}$ & $\mathrm{I}^{r e l}$ & $\begin{array}{c}\text { PDF 24-1370 } \\
\mathrm{d}\end{array}$ & $\mathrm{I}^{\text {rel }}$ \\
\hline 0.9799 & 2 & $329+$ & & & & \\
\hline 0.9751 & 2 & $158+$ & & & & \\
\hline 0.9717 & 2 & 3110 & & & & \\
\hline 0.9701 & $<1$ & 163 & & & & \\
\hline 0.9641 & 5 & 2212 & 0.9640 & 8 & & \\
\hline 0.9629 & 1 & 415 & & & & \\
\hline 0.9617 & 0 & 059 & & & & \\
\hline 0.9589 & 2 & 338 & 0.9600 & 8 & & \\
\hline 0.9574 & 2 & 2311 & & & & \\
\hline 0.9516 & 3 & 1411 & & & & \\
\hline 0.9498 & $<1$ & 406 & & & & \\
\hline 0.9481 & 2 & 424 & & & & \\
\hline 0.9366 & 1 & $\begin{array}{llll}3 & 0 & 11\end{array}$ & & & & \\
\hline 0.9347 & $<1$ & 165 & & & & \\
\hline 0.9333 & 3 & 257 & & & & \\
\hline 0.9246 & $<1$ & 2410 & & & & \\
\hline 0.9168 & $<1$ & 260 & 0.9158 & 7 & & \\
\hline 0.9122 & 3 & 417 & & & & \\
\hline 0.9106 & $<1$ & 352 & & & & \\
\hline 0.9090 & 2 & $262+$ & & & & \\
\hline 0.9072 & $<1$ & 426 & & & & \\
\hline
\end{tabular}

Table 12: (continued). Calculated and observed patterns (Boehme et al. and 24-1370) for orthorhombic $\mathrm{UTe}_{2}$. 


\begin{tabular}{|c|c|c|c|c|c|c|}
\hline d & Irel & $\begin{array}{c}\text { Calculated } \\
\text { hk } \ell\end{array}$ & $\begin{array}{c}\text { Boehme et al. [2] } \\
d\end{array}$ & $I^{r e l}$ & $\begin{array}{c}\text { PDF 24-1370 } \\
\text { d }\end{array}$ & $I^{r e l}$ \\
\hline 0.8994 & 2 & $1510+$ & 0.8993 & 8 & & \\
\hline 0.8937 & $<1$ & 408 & & & & \\
\hline 0.8882 & 2 & $354+$ & & & & \\
\hline 0.8867 & 3 & $264+$ & & & & \\
\hline 0.8817 & $<1$ & 0511 & & & & \\
\hline 0.8799 & 1 & 435 & & & & \\
\hline 0.8728 & $<1$ & 0016 & & & & \\
\hline 0.8711 & 6 & 1215 & & & & \\
\hline 0.8607 & 3 & $440+$ & & & & \\
\hline 0.8580 & 0 & $428+$ & & & & \\
\hline 0.8493 & $<1$ & 3013 & & & & \\
\hline 0.8465 & $<1$ & 2412 & & & & \\
\hline 0.8407 & 3 & 437 & & & & \\
\hline 0.8357 & 2 & $169+$ & & 0.8358 & 11 & \\
\hline 0.8343 & $<1$ & 4010 & & & & \\
\hline 0.8320 & 2 & 174 & & & & \\
\hline 0.8210 & 3 & 361 & & & & \\
\hline 0.8194 & 3 & 503 & & & & \\
\hline
\end{tabular}

Table 12: (continued). Calculated and observed patterns (Boehme et al. and 24-1370) for orthorhombic: UTe. 


\section{2 $\mathrm{UTe}_{2}-$ Tetragonal}

Ferro[10] first reported $\mathrm{UTe}_{2}$ and indexed it as tetragonal with a cell of $\mathrm{a}=$ $4.006 \AA$ and $\mathrm{c}=7.471 \AA$. This phase was later shown to be not UT.e 2 but UOTe by Klein-Haneveld and Jellinek[14]. Slovyanskikh et al.[27] reported an unindexed powder pattern for $\mathrm{UTe}_{2}$ and referred to the structure as tetragonal. It is not clear that this reference is not simply a repetition of the Ferro claim. Their powder pattern has been abstracted as PDF 21-1405. Grønvold[13] refer to a report by Pletyushkin[23] claiming a tetragonal form with lattice parameters of $\mathrm{a}=4.016 \AA$ and $\mathrm{c}=7.49 \AA$. Since these lattice parameters are similar to the original erroneous report on $\mathrm{UTeO}$, this report is also open to question.

Klein Haneveld and Jellinek[15] reported a solid solution range for tetragonal $\mathrm{UTe}_{2-x}$ with $\mathrm{x}$ varying from 0 to 0.13 . They later claimed this phase only to be stable in the presence of a small amount of Ge. However this material is listed in the Crystal Data data base as UTeGe. This material is questionable. The authors did report a crystal structure while thinking this phase was stoichiometric $\mathrm{UTe}_{2}$. Since then the structure of this material has been determined as UTeGe with a reduced unit cell of $\mathrm{a}=4.11 \AA$ and $\mathrm{c}=$ $9.27 \AA$. The non-reduced cell reported in later articles has $c=17.60 \AA$.

In summary, each of the reports of tetragonal $\mathrm{UTe}_{2}$ is open to serious question. There has not been an unambiguous report to date, establishing the existence of this phase. 


\subsection{UTe $\mathrm{UT}_{2}$-Cubic}

Recently Pfoertsch and Ruud[24] reported a powder pattern (PDF 35-1483) for a cubic form of $\mathrm{UTe}_{2}$. They propose a space group of $\mathrm{Pa} 3$ for it. This is the same space group for pyrite $\left(\mathrm{FeS}_{2}\right)$ type structures and the PDF card states that this material has the pyrite structure. We have attempted to simulate this pattern using the structure of pyrite as determined by Brostigen and Kjekshus[5] with $U$ in the $4(a)$ site and the Te in $8(\mathrm{c})$ with $\mathrm{x}$ set to .3840 and $\mathrm{a}=5.469$. This computation and the published pattern are shown in Table 13. It is clear from the poor agreement between the calculated and observed intensities that this material does not have the pyrite structure. Even more noticeable is that the density calculates to $20.03 \mathrm{~g} / \mathrm{cm}^{3}$. The indexing on the card is consistent with the reported cell parameter of 5.469 $\AA$.

In order to make the density equal to a more reasonable $10.0 \mathrm{~g} / \mathrm{cm}^{3}$ rather than $20 \mathrm{~g} / \mathrm{cm}^{3}$ in a cubic cell with edge $=5.469 \AA$, you must put 2 uranium atoms and 4 tellurium atoms into the Primitive cell. (The hk $\ell^{\prime}$ s require that the cell be primitive), This can only be done in a cubic cell by putting $U$ at the origin and Te at either $1 / 4,1 / 4,1 / 4$ or at $3 / 4,3 / 4,3 / 4$. We have computed these models also. In neither case do we get anything remotely resembling the reported pattern.

Since this is the first and only report of a cubic $\mathrm{UTe}_{2}$ and since no chemical analysis confirmation was carried out, we must doubt the validity of this report. The sample, originally from China[25], has been lost so further 
testing is impossible. We must conclude that this sample is not a form of $\mathrm{UTe}_{2}$. 


\begin{tabular}{|c|c|c|c|c|c|}
\hline $\mathrm{d}$ & $I^{r e l}$ & $\begin{array}{c}\text { Calculated } \\
\text { hk } \ell\end{array}$ & $d$ & $\mathrm{I}^{\mathrm{rel}}$ & $\begin{array}{c}\text { PDF } 35-1483 \\
\text { hk } \ell\end{array}$ \\
\hline 3.158 & 38 & 111 & 3.154 & 100 & 111 \\
\hline 2.734 & 94 & 200 & 2.735 & 40 & 200 \\
\hline 2.446 & 63 & 210 & & & \\
\hline 2.233 & 52 & 211 & 2.230 & 10 & 211 \\
\hline 1.9336 & 49 & 220 & 1.932 & 50 & 220 \\
\hline 1.8230 & 1 & 221 & 1.823 & 6 & 221 \\
\hline 1.6490 & 100 & 311 & 1.6489 & 45 & 311 \\
\hline 1.5788 & 15 & 222 & 1.5783 & 10 & 222 \\
\hline 1.5168 & 18 & 023 & & & \\
\hline 1.4617 & 23 & $321+$ & & & \\
\hline & & & 1.3678 & 6 & 400 \\
\hline 1.3264 & 1 & $410+$ & & & \\
\hline 1.2547 & 9 & 331 & 1.2554 & 18 & 331 \\
\hline 1.2229 & 12 & $420+$ & 1.2236 & 12 & 420 \\
\hline 1.1934 & 9 & 421 & & & \\
\hline 1.1660 & 4 & 332 & & & \\
\hline 1.1164 & 11 & 422 & 1.1168 & 14 & 422 \\
\hline
\end{tabular}

Table 13: Calculated pattern for the postulated pyrite structured $\mathrm{UTe}_{2}$ (left) and the reported (35-1483) pattern. 


\section{$10 \mathrm{UTe}_{2.5}$}

Slovyanskikh et al.[27] reported three phases in between $\mathrm{UTe}_{2}$ and $\mathrm{UTe}_{3}$. These are $\mathrm{U}_{3} \mathrm{Te}_{7}\left(\mathrm{UTe}_{2.333}\right.$ abstracted as PDF 21-1402), $\mathrm{U}_{2} \mathrm{Te}_{5}\left(\mathrm{UTe}_{2.5}\right.$ abstracted as PDF 21-1409) and $\mathrm{U}_{3} \mathrm{Te}_{8}$ (UTe ${ }_{2,667}$ abstracted as PDF 21-1406). Grønvold et al.[13] argue that there is only one phase in this region, namely that of $\mathrm{U}_{2} \mathrm{Te}_{5}$. They refer to a pattern published in a contract report to the International Atomic Energy Agency[12] that has never been abstracted in to the open literature. We therefore have included this pattern in Table 14. This pattern was reporied to be taken on a Guinier camera. The d's have been computed from the reported $\sin ^{2} \theta$ values and the intensities have been left as visual estimates. We should note that in this study the authors simply prepared compositions of various stoichiometries and reported diffraction patterns of the resulting material. It is possible that their patterns are multi-phase.

$\mathrm{UTe}_{2.5}$ was observed in the recent study by Boehme et al.[2] in mixtures containing $\mathrm{UTe}_{2}$ and $\mathrm{UTe}_{3}$. They indexed it as orthorhombic with a unit cell similar to that reported for UTes; however, a uranium deficient UTe model failed to predict any pattern resembling their observed pattern. No further structural investigation is possible without a better starting model. We conclude that $\mathrm{UTe}_{2.5}$ is a real phase and that the Gronvold et al.[1.3] pattern shown in table 14 probably was of a mixture containing this phase. 


\begin{tabular}{|c|c|c|c|c|}
\hline $\begin{array}{l}\text { Boehtne et al. } \\
\text { d }\end{array}$ & $1^{\text {rel }}$ & hike & $\begin{array}{l}\text { Gronvold et al. } \\
\text { d }\end{array}$ & $1^{\text {rel }}$ \\
\hline 17.024 & 14 & $\begin{array}{llll}0 & 0 & 1\end{array}$ & & \\
\hline 8.546 & 18 & 002 & & \\
\hline 3.702 & 17 & 0003 & & \\
\hline 4.280 & 18 & 004 & & \\
\hline 3.926 & 3 & 014 & & \\
\hline 3.714 & 2 & 023 & 3.442 & vw \\
\hline 3.181 & 100 & 121 & $\begin{array}{l}3.182 \\
3.027\end{array}$ & $\begin{array}{l}\text { vo } \\
\mathrm{m}\end{array}$ \\
\hline 2.738 & 9 & 016 & $\begin{array}{l}2.778 \\
2.433\end{array}$ & m \\
\hline 2.374 & 17 & 133 & $\begin{array}{l}2.376 \\
2.362 \\
2.257\end{array}$ & $\begin{array}{l}v w \\
w \\
v w\end{array}$ \\
\hline 2.230 & 7 & 134 & $\begin{array}{l}2.173 \\
2.092 \\
1.8623\end{array}$ & $\begin{array}{l}\text { vw } \\
\text { rw }\end{array}$ \\
\hline 1.714 & 30 & 116 & $\begin{array}{l}1.7202 \\
1.6706\end{array}$ & $\begin{array}{r}r w \\
w\end{array}$ \\
\hline 1.617 & 2 & 240 & & \\
\hline 1.819 & 4 & 0310 & 1.3189 & $m$ \\
\hline 1.371 & 3 & $0 \in 7$ & $\begin{array}{l}1.3709 \\
1.3116\end{array}$ & $\begin{array}{l}w \\
w\end{array}$ \\
\hline $\begin{array}{l}1.224 \\
1.101 \\
\end{array}$ & $\begin{array}{l}6 \\
5\end{array}$ & $\begin{array}{l}0511 \\
091\end{array}$ & & 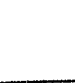 \\
\hline
\end{tabular}

Table 14: Boehme et al, and Grønvold et al. patterns for UTe $\mathbf{U}_{2.5}$. 


\section{$11 \mathrm{UTe}_{3}$}

\section{$11.1 \alpha \mathrm{UTe}_{3}$}

This phase was first published by Slovyanskikh et al.[27]. Their very poor camera pattern was abstracted and remains in the current PDF as 21-1403. Breeze et al.[3] indexed their pattern as monoclinic (abstracted as PDF 27$929)$ with the parameters shown in Table 1. In addition they suggested that it might be isomorphous with $\mathrm{ZrS}_{3}$. The $\mathrm{ZrS}_{3}$ type structures were determined by Furuseth et al.[11], however, more recently the more wilalogous isomorphous structure of $\mathrm{USe}_{3}$ has been determined by Salem et al.[29]. Our computation is based on the Salem et al. model shown in Tables 1 and 3 and is compared to the two older experimental patterns and the recent one of Boehme al.[2] in Table 15. 


\begin{tabular}{|c|c|c|c|c|c|c|c|c|}
\hline d & $\mathrm{I}^{\mathrm{rel}}$ & $\begin{array}{c}\text { Calculated } \\
\text { hk } \ell\end{array}$ & $\begin{array}{c}\text { Boehme et al. } \\
\text { d }\end{array}$ & Irel & $\begin{array}{c}27-929 \\
\text { d }\end{array}$ & $I^{r e l}$ & $\begin{array}{r}21-1403 \\
d\end{array}$ & $I^{r e l}$ \\
\hline 10.200 & 44 & 001 & 10.239 & 59 & 10.2 & 50 & & \\
\hline 6.031 & 4 & 100 & 6.048 & 5 & & & & \\
\hline 5.540 & 26 & -101 & 5.546 & 8 & 5.54 & 20 & & \\
\hline 5.100 & 10 & 002 & 5.118 & 26 & 5.08 & 30 & 5.11 & 30 \\
\hline 4.901 & 21 & 101 & 4.915 & 6 & 4.89 & 20 & & \\
\hline \multirow[t]{2}{*}{4.192} & 5 & -10.2 & 4.198 & 3 & & & & \\
\hline & & 011 & 3.902 & $<1$ & & & & \\
\hline 3.400 & 3 & 003 & 3.410 & 6 & & & & \\
\hline 3.256 & 100 & 012 & 3.258 & 100 & 3.25 & 100 & 3.25 & 20 \\
\hline \multirow[t]{3}{*}{3.008} & 12 & $-201+$ & 3.205 & 6 & & & & \\
\hline & & 200 & & & 3.01 & 30 & 3.11 & 100 \\
\hline & & -201 & 3.017 & 16 & & & & \\
\hline 2.978 & 3 & -112 & 2.973 & 1 & & & 2.88 & 10 \\
\hline 2.788 & 20 & 201 & $2.78 \pi$ & 29 & & & 2.83 & 30 \\
\hline 2.770 & 24 & $-202+$ & & & 2.770 & 50 & & \\
\hline 2.650 & 7 & 013 & 2.653 & 5 & & & & \\
\hline 2.550 & 6 & 004 & 2.556 & 31 & 2.545 & 40 & 2.57 & 100 \\
\hline 2.529 & 20 & -113 & 2.531 & 4 & & & & \\
\hline 2.475 & 5 & .104 & 2.479 & 4 & & & 2.48 & 20 \\
\hline 2.451 & 33 & $-211+$ & 2.455 & 19 & 2.449 & 60 & & \\
\hline 2.430 & 6 & -203 & 2.436 & 6 & & & & \\
\hline 2.335 & 22 & 113 & 2.325 & 14 & & & 2.33 & 20 \\
\hline
\end{tabular}

Table 15: Calculated pattern for $\alpha$ UTe 3 (left) and the observed (27-929 and 21-1403). 


\begin{tabular}{|c|c|c|c|c|c|c|c|c|}
\hline$d$ & $I^{r e l}$ & $\begin{array}{c}\text { Caiculated } \\
\text { hk } \ell\end{array}$ & $\begin{array}{c}\text { Boehme et al. } \\
\text { d }\end{array}$ & $\mathrm{I}^{\mathrm{rel}}$ & $\begin{array}{c}27-929 \\
\mathrm{~d}\end{array}$ & $I^{r e l}$ & $\begin{array}{r}21-1403 \\
\mathrm{~d}\end{array}$ & $\mathrm{I}^{\mathrm{rel}}$ \\
\hline 2.328 & 26 & 211 & & & 2.323 & 50 & 2.25 & 30 \\
\hline 2.317 & 16 & -212 & & & & & & \\
\hline 2.239 & 5 & 104 & 2.246 & 4 & & & & \\
\hline 2.184 & 8 & 014 & 2.187 & 10 & 2.181 & 30 & 2.19 & 30 \\
\hline 2.136 & 6 & -114 & 2.137 & 2 & & & & \\
\hline 2.115 & 25 & $020+$ & 2.116 & 3 & 2.107 & 50 & 2.12 & 10 \\
\hline 2.096 & 5 & -204 & 2.111 & 12 & & & 2.07 & 20 \\
\hline 2.071 & 2 & 021 & 2.068 & 2 & & & 2.05 & 20 \\
\hline & & 005 & 2.045 & 3 & & & & \\
\hline 2.020 & 6 & -105 & 2.024 & 4 & & & 2.03 & 20 \\
\hline & & 120 & 1.996 & 11 & & & & \\
\hline 1.9759 & 3 & $-121+$ & 1.973 & $<1$ & & & & \\
\hline 1.9537 & 2 & 022 & & & & & & \\
\hline 1.9419 & 3 & 121 & & & & & & \\
\hline 1.9222 & 2 & 301 & & & & & & \\
\hline 1.8914 & 5 & $213+$ & 1.894 & 2 & 1.887 & 30 & & \\
\hline 1.8782 & 4 & -214 & 1.880 & 2 & & & & \\
\hline 1.8556 & 6 & 105 & 1.861 & 3 & & & 1.86 & 40 \\
\hline 1.8467 & 3 & -303 & 1.841 & 1 & & & & \\
\hline 1.8276 & 4 & $-311+$ & 1.820 & 2 & & & 1.82 & 10 \\
\hline 1.7828 & 3 & $-312+$ & 1.782 & 1 & & & 1.78 & 10 \\
\hline 1.7500 & 5 & 311 & 1.753 & $<1$ & & & & \\
\hline
\end{tabular}

Table 15: (continued). Calculated pattern for $\alpha \mathrm{UTe}_{3}$ (left) and the observed (27-929 and 21-1403). 


\begin{tabular}{|c|c|c|c|c|c|c|c|c|}
\hline d & $\mathrm{I}^{\text {rel }}$ & $\begin{array}{c}\text { Calculated } \\
\text { hk } \ell\end{array}$ & $\begin{array}{c}\text { Boehme et al. } \\
\text { d }\end{array}$ & $\mathrm{I}^{\text {rel }}$ & $\begin{array}{c}27-929 \\
\text { d }\end{array}$ & $\mathrm{I}^{\text {rel }}$ & $\begin{array}{r}21-1403 \\
d\end{array}$ & $\mathrm{I}^{\text {rel }}$ \\
\hline 1.7301 & 4 & $-221+$ & 1.730 & 1 & & & & \\
\hline & & $006+$ & 1.704 & 9 & & & & \\
\hline 1.7000 & 7 & -304 & 1.700 & 4 & 1.697 & 30 & 1.70 & 100 \\
\hline 1.6924 & 6 & -313 & & & & & & \\
\hline 1.6850 & 8 & 221 & & & 1.683 & 30 & & \\
\hline 1.6810 & 10 & -222 & 1681 & 2 & & & & \\
\hline & & 214 & 1.681 & 2 & & & & \\
\hline 1.6337 & 4 & $\begin{array}{lll}3 & 03\end{array}$ & & & & & & \\
\hline 1.6279 & 3 & 024 & 1.628 & 1 & & & 1.62 & 5 \\
\hline 1.6080 & 2 & -124 & & & & & & \\
\hline 1.5954 & 2 & -223 & & & & & & \\
\hline 1.5767 & 2 & $-116+$ & 1.579 & 1 & & & 1.58 & 20 \\
\hline 1.5432 & 3 & -305 & & & & & & \\
\hline 1.5377 & 3 & 124 & 1.540 & 1 & & & & \\
\hline 1.5224 & 5 & $-401+$ & 1.525 & 2 & 1.524 & 30 & 1.50 & 1.0 \\
\hline 1.4954 & 3 & 223 & & & & & & \\
\hline 1.4888 & 5 & $-224+$ & 1.484 & 2 & & & 1.48 & 20 \\
\hline 1.4783 & 4 & $-216+$ & & & & & 1.47 & 10 \\
\hline 1.4606 & 4 & -125 & 1.460 & $<1$ & & & & \\
\hline 1.4498 & 2 & -315 & 1.450 & $<1$ & & & 1.42 & 10 \\
\hline 1.3983 & 2 & 314 & & & & & & \\
\hline 1.3949 & 5 & 125 & 1.396 & 1 & & & & \\
\hline
\end{tabular}

Table 15: (continued). Calculated pattern for $\alpha \mathrm{UTe}_{3}$ (left) and the observed (27-929 and 21-1403). 


\begin{tabular}{|c|c|c|c|c|c|c|c|c|}
\hline d & $\mathrm{I}^{\mathrm{rel}}$ & $\begin{array}{c}\text { Calculated } \\
\text { hik } \ell\end{array}$ & $\begin{array}{c}\text { Boehme et al. } \\
\text { d }\end{array}$ & Irel & $\begin{array}{c}27-929 \\
\text { d }\end{array}$ & Irel & $\begin{array}{r}21-1403 \\
d\end{array}$ & $\mathrm{I}^{\text {rel }}$ \\
\hline 1.3910 & 4 & -323 & & & & & & \\
\hline 1.3821 & 5 & $411+$ & 1.384 & 2 & & & 1.380 & 30 \\
\hline 1.3762 & 5 & $-413+$ & 1.376 & 2 & & & & \\
\hline 1.3590 & 6 & 032 & & & & & & \\
\hline 1.3290 & 2 & 216 & 1.326 & 2 & & & 1.327 & 30 \\
\hline 1.3250 & 6 & $026+$ & & & & & & \\
\hline 1.3205 & 5 & -217 & 1.323 & 1 & & & & \\
\hline 1.3154 & 2 & 132 & & & & & 1.318 & 30 \\
\hline 1.3063 & 2 & 117 & 1.309 & 1 & & & 1.307 & 20 \\
\hline 1.3024 & 2 & 033 & & & & & & \\
\hline 1.2929 & 3 & 323 & 1.294 & 1 & & & & \\
\hline 1.2873 & 2 & -133 & 1.282 & 1 & & & 1.285 & 10 \\
\hline 1.2788 & 3 & 315 & 1.278 & 1 & & & 1.278 & 30 \\
\hline 1.2767 & 4 & $-231+$ & 1.276 & 1 & & & & \\
\hline 1.2593 & 3 & $133+$ & & & & & & \\
\hline 1.2566 & 3 & -232 & & & & & & \\
\hline 1.2467 & 3 & -325 & 1.246 & 1 & & & 1.248 & 10 \\
\hline 1.2445 & 2 & -415 & & & & & 1.241 & 10 \\
\hline 1.2356 & 4 & $-421+$ & & & & & & \\
\hline 1.2252 & 2 & -134 & & & & & & \\
\hline 1.2207 & 3 & 018 & & & & & 1.222 & 90 \\
\hline
\end{tabular}

Table 15: (continued). Calculated pattern for $\alpha \mathrm{UTe}_{3}$ (left) and the observed (27-929 and 21-1403). 


\begin{tabular}{|c|c|c|c|c|c|c|c|c|}
\hline$d$ & $I^{r e l}$ & $\begin{array}{c}\text { Calculated } \\
\text { hk } \ell\end{array}$ & $\begin{array}{c}\text { Boehme et al. } \\
\text { d }\end{array}$ & Irel & $\begin{array}{c}27-929 \\
\mathrm{~d} \\
\end{array}$ & $I^{\text {rel }}$ & $\begin{array}{r}21-1403 \\
d\end{array}$ & $\mathrm{I}^{\mathrm{rel}}$ \\
\hline 1.2133 & 5 & $-317+$ & & & & & & \\
\hline & & 119 & $1.11 y$ & $<1$ & & & & \\
\hline 1.1697 & 3 & $316+$ & & & & & & \\
\hline 1.1135 & 3 & $-514+$ & & & & & 1.116 & 20 \\
\hline 1.0997 & 3 & 512 & & & & & & \\
\hline 1.0575 & 2 & 040 & & & & & & \\
\hline 1.0550 & 3 & $326+$ & ' & & & & & \\
\hline 1.0517 & 3 & $-522+$ & & & & & 1.052 & 10 \\
\hline 1.0360 & 2 & 504 & & & & & & \\
\hline & & 0010 & 1.023 & 1 & & & & \\
\hline 1.0150 & 3 & $431+$ & & & & & 1.022 & 50 \\
\hline 1.0127 & 3 & $-433+$ & & & & & 1.001 & 50 \\
\hline 1.0098 & 2 & -2010 & & & & & 0.998 & 20 \\
\hline 0.9916 & 2 & $0110+$ & & & & & 0.993 & 40 \\
\hline 0.9896 & 2 & $228+$ & & & & & 0.991 & 30 \\
\hline 0.9888 & 2 & 241 & & & & & & \\
\hline 0.9880 & 2 & -242 & & & & & & \\
\hline 0.9850 & 2 & -229 & & & & & & \\
\hline 0.9563 & 2 & $417+$ & & & & & & \\
\hline 0.9457 & 3 & $038+$ & & & & & & \\
\hline 0.9444 & 3 & $-526+$ & & & & & & \\
\hline 0.9422 & 3 & $-337+$ & & & & & & \\
\hline
\end{tabular}

Table 15: (continued). Calculated pattern for $\alpha \mathrm{UTe}_{3}$ (left) and the observed (27-929 and 21-1403). 


\section{$11.2 \beta \mathrm{UTe}_{3}$ and $\mathrm{UTe}_{3.4}$}

Slovyanskikh et al.[27] reported a crude powder pattern for a material with $77 \%$ Te. Later, Breeze et al.[3] reported a phase with the composition $\mathrm{UTe}_{3.38}$ as being tetragonal with cell parameters of $\mathrm{a}=8.703 \AA$ and $\mathrm{c}=$ $13.09 \AA$ and a powder pattern similar to that of Slovyanskikh et al.[27]. Their powder pattern was abstracted as PDF 24-1369. Suski[32] confirmed this phase reporting lattice parancters of $\mathrm{a}=8.672 \AA$ and $\mathrm{c}=13.014 \AA$. Recently, Boehme et al.[2] liave proven the existence of a UTe $\mathrm{UT}_{3.4}$ composition and established an improved powder pattern.

Noel and Levet[22] liave just published the crystal structure of a phase they call $\beta \mathrm{UTe}_{3}$ which has the $\mathrm{NdTe}_{3}$ structure. Their paper claims to disprove that the $\mathrm{UTe}_{3.38}$ phase exists and asserts that it was probably a mixture of $\beta \mathrm{UTe}_{3}$ and free Te. The calculated powder pattern for $\beta \mathrm{UTe}_{3}$ shown in Table 16, show's reasonable agreement with the older published patterns and quite a lot of similarity with the higher quality pattern of Boehme et al.[2] for UTe 3.4 . Note that the cells for the three patterns listed in Table 16 differ, producing different likl's. The calculated UTe 3 pattern is based on the Noel and Lever [22] rell given in Table 1. The PDF 24-1369 pattern is for UTez.38 based on thre totragonal cell of Slovyanskikh et al.[27] with $\mathrm{a}=8.703 \AA$ and $\mathrm{c}=13.0 \times\left(\mathrm{A} \mathrm{A}\right.$. The orthorhombic pattern for $\mathrm{UTe}_{3}$ of Boehme et al. [2] was indexed with $a=(0.382 \AA \mathrm{b}=6.475 \AA$ and $\mathrm{c}=12.408$ $\AA$

We do not believe the worti of Nonl and Levet is sufficient to prove that 
a cation deficient compound does not exist. In fact, if the $\mathrm{UTe}_{3}$ compound were the correct phase in the recent accurate diffraction work, then froe tellurium should have been observed. The most reasonable explanation of the experimental observations is that the structure of $\beta \mathrm{UTe}_{3}$ allows a range of uranium deficiencies covering the range from 3.0 to at least $3.4 \mathrm{Te}$. 


\begin{tabular}{|c|c|c|c|c|c|c|c|c|}
\hline $\begin{array}{c}\mathrm{UTe}_{3.4} \\
\mathrm{~d}\end{array}$ & $\mathrm{I}^{\mathrm{rel}}$ & $\begin{array}{c}\text { Boehme et al.[2] } \\
\text { hk } \ell\end{array}$ & $\begin{array}{c}\mathrm{UTe}_{3.38} \\
\mathrm{~d}\end{array}$ & $I^{r e l}$ & $\begin{array}{c}24-1369 \\
\text { hk } \ell\end{array}$ & $\begin{array}{c}\mathrm{UTe}_{3} \\
\mathrm{~d}\end{array}$ & Irel & $\begin{array}{c}\text { Calculated } \\
\text { hk } \ell\end{array}$ \\
\hline 12.426 & 17 & 0001 & & & & 12.379 & 11 & 020 \\
\hline 6.484 & $<1$ & 010 & & & & & & \\
\hline 6.202 & 30 & 002 & & & & 6. 89 & 15 & 040 \\
\hline & & & 5.19 & 40 & 102 & & & \\
\hline 4.271 & $<1$ & 111 & & & & 4.266 & 10 & 021 \\
\hline 4.138 & $<1$ & 003 & & & & 4.126 & 1 & 060 \\
\hline 3.470 & 2 & 103 & & & & & & \\
\hline 3.196 & 9 & 200 & & & & 3.186 & 33 & 111 \\
\hline 3.102 & 100 & 004 & 3.07 & 100 & 220 & 3.095 & 42 & 080 \\
\hline 3.056 & 18 & 113 & & & & 3.055 & 10 & 061 \\
\hline & & & & & & 2.994 & 100 & 131 \\
\hline 2.886 & 49 & 120 & 2.877 & 100 & 114 & & & \\
\hline 2.835 & 1 & 202 & & & & & & \\
\hline 2.802 & $<1$ & 014 & & & & & & \\
\hline 2.791 & $<1$ & 104 & & & & 2.791 & 16 & 170 \\
\hline 2.617 & 43 & 122 & 2.608 & 100 & 204 & & & \\
\hline 2.318 & 10 & 015 & 2.319 & 40 & $\begin{array}{lll}313 \\
\end{array}$ & & & \\
\hline 2.177 & 16 & 115 & 2.172 & 60 & 400 & 2.174 & 7 & 0101 \\
\hline 2.125 & $<1$ & 031 & & & & 2.133 & 3 & 240 \\
\hline 2.067 & 10 & 006 & 2.054 & 40 & 402 & 2.063 & 4 & 0120 \\
\hline
\end{tabular}

Table 16: Observed patterns for $\mathrm{UTe}_{3.4}$ Boehme et al. and $\mathrm{UTe}_{3.38}$ (24$1369)$, and the calculated pattern for $\beta \mathrm{UTe}_{3}$. 


\begin{tabular}{|c|c|c|c|c|c|c|c|c|}
\hline $\begin{array}{c}\mathrm{UTe}_{3.4} \\
\mathrm{~d}\end{array}$ & $I^{r e l}$ & $\begin{array}{c}\text { Boehme et al.[2] } \\
\text { hk } \ell\end{array}$ & $\begin{array}{c}\mathrm{U}^{\prime} \mathrm{Te}_{3.38} \\
\mathrm{~d}\end{array}$ & $I^{r e l}$ & $\begin{array}{c}24-1369 \\
\text { hk } \ell\end{array}$ & $\begin{array}{c}\mathrm{U}^{\prime} \mathrm{Te}_{3} \\
\mathrm{~d}\end{array}$ & $\mathrm{I}^{\text {rel }}$ & $\begin{array}{c}\text { Calculated } \\
\text { hk } \ell\end{array}$ \\
\hline 2.013 & $<1$ & 302 & 1.811 & 30 & 404 & 2.017 & 1 & 1110 \\
\hline 1.772 & 7 & 007 & 1.775 & 60 & 423 & 1.768 & 3 & 0140 \\
\hline 1.619 & 2 & 040 & $\begin{array}{l}1.615 \\
1.537\end{array}$ & $\begin{array}{l}40 \\
50\end{array}$ & $\begin{array}{l}503 \\
440\end{array}$ & & & \\
\hline 1.469 & $<1$ & 118 & 1.495 & 30 & 442 & 1.465 & 4 & 0161 \\
\hline 1.378 & 4 & 009 & $\begin{array}{l}1.375 \\
1.356\end{array}$ & $\begin{array}{l}50 \\
40\end{array}$ & $\begin{array}{l}620 \\
534\end{array}$ & 1.380 & 15 & 351 \\
\hline 1.327 & 3 & 145 & 1.325 & 50 & 604 & 1.326 & 11 & 1171 \\
\hline 1.319 & 7 & 119 & & & & 1.316 & 1 & 0181 \\
\hline 1.283 & 1 & 430 & & & & 1.281 & 4 & 1152 \\
\hline 1.227 & $<1$ & 512 & & & & & & \\
\hline 1.175 & $<1$ & 147 & & & & & & \\
\hline 1.162 & $<1$ & 039 & & & & 1.167 & 2 & 283 \\
\hline 1.128 & 2 & 00011 & & & & 1.125 & 2 & 0220 \\
\hline 1.102 & $<1$ & 351 & & & & 1.107 & 1 & 1211 \\
\hline 1.090 & $<1$ & 329 & & & & 1.092 & 1 & 0221 \\
\hline 1.034 & $<1$ & 0012 & & & & 1.032 & 1 & 0240 \\
\hline 1.019 & $<1$ & 261 & & & & 1.020 & 5 & 1212 \\
\hline
\end{tabular}

Table 16: (Continued). Observed patterns for $\mathrm{UTe}_{3.4}$ Boehme et al. and $\mathrm{UTe}_{3.38}$ (24-1369), and the calculated pattern for $\beta \mathrm{UTe}_{3}$. 


\section{$12 \mathrm{UTe}_{5}$}

The highest percentage of tellurium in a uranium telluride has been reported by Slovyanskikh et al.[27] as U' ' $e_{5}$. It has been confirmed by Noel[20] and his powder pattern has been abstracted as PDF 36.1291. In 1985 Noel[21] published the crystal structure of this phase which is of a new type. The crystal structure information is given in Tables 1 and 3 . This model was used to compute the powder pattern shown in Table 17 . The recently reported experimental pattern of Boehme et al.[2] is included. The new pattern reports a number of weak reflections that calculate but were not previously reported. 


\begin{tabular}{|c|c|c|c|c|c|c|}
\hline d & $\mathrm{I}^{\mathrm{rel}}$ & $\begin{array}{c}\text { Calculated } \\
\text { hk } \ell\end{array}$ & $\begin{array}{c}36-1201 \\
d\end{array}$ & $I^{r e l}$ & $\begin{array}{c}\text { Boehme el al. } \\
\text { d }\end{array}$ & $I^{r e l}$ \\
\hline 8.958 & 12 & 200 & 8.952 & 5 & 8.959 & 13 \\
\hline 6.789 & 100 & 210 & $6.8 \cap \Omega$ & 40 & 6.809 & 40 \\
\hline 5.203 & 18 & 020 & 5.215 & 10 & 5.211 & 22 \\
\hline 4.499 & 1 & 220 & & & 4.502 & 1 \\
\hline 4.108 & 3 & 101 & & & 4.180 & 1 \\
\hline & & 410 & & & 4.117 & 3 \\
\hline 3.911 & 5 & 011 & & & 3.918 & 3 \\
\hline 3.821 & 1 & 111 & & & & \\
\hline 3.584 & 8 & 211 & & & 3.591 & 4 \\
\hline 3.446 & 18 & 301 & 3.447 & 5 & 3.451 & 11 \\
\hline 3.272 & 66 & 311 & 3.260 & 20 & 3.275 & 44 \\
\hline 3.235 & 7 & 230 & & & & \\
\hline 3.078 & 69 & $221+$ & 3.079 & 20 & 3.079 & 50 \\
\hline 2.986 & 1 & $600+$ & & & & \\
\hline 2.873 & 75 & $321+$ & 2.870 & 50 & 2.876 & 66 \\
\hline 2.743 & 18 & $43 \mathrm{u}+$ & 2.743 & 30 & 2.747 & 29 \\
\hline 2.680 & 21 & $031+$ & 2.679 & 5 & 2.684 & 14 \\
\hline 2.650 & 22 & $131+$ & 2.647 & 5 & 2.652 & 16 \\
\hline 2.602 & 39 & $040+$ & & & & \\
\hline 2.590 & 73 & $620+$ & 2.595 & 100 & 2.592 & 100 \\
\hline 2.567 & 18 & 231 & & & & \\
\hline 2.498 & 6 & 240 & 2.498 & 5 & 2.503 & 6 \\
\hline 2.445 & 30 & $331+$ & 2.445 & 15 & 2.450 & 23 \\
\hline
\end{tabular}

Table 17: Calculated pattern for U'Tes (left) and observed, 36-1291 (middle), Boehme et al. (right). 


\begin{tabular}{|c|c|c|c|c|c|c|}
\hline d & $I^{r e l}$ & $\begin{array}{c}\text { Calculated } \\
\text { hke }\end{array}$ & $\begin{array}{c}36-1291 \\
\mathrm{~d}\end{array}$ & $I^{r e l}$ & $\begin{array}{c}\text { Boehme el al. } \\
\text { d }\end{array}$ & Irel \\
\hline 2.418 & 14 & 521 & 2.417 & 5 & 2.421 & 10 \\
\hline 2.373 & 24 & 611 & 2.371 & 10 & 2.375 & 19 \\
\hline 2.300 & 5 & 431 & 2.301 & 2 & 2.304 & 3 \\
\hline 2.263 & 6 & 630 & 2.261 & 5 & 2.266 & 5 \\
\hline 2.250 & 3 & $440+$ & & & & \\
\hline 2.198 & 6 & $141+$ & & & & \\
\hline 2.189 & 7 & $810+$ & 2.187 & 5 & 2.191 & 7 \\
\hline 2.150 & 7 & 241 & 2.151 & 5 & 2.154 & 4 \\
\hline 2.146 & 6 & 531 & & & & \\
\hline 2.110 & 1 & 002 & & & & \\
\hline 2.096 & 3 & 102 & & & 2.086 & 1 \\
\hline 2.054 & 23 & 112 & 2.055 & 5 & 2.059 & 8 \\
\hline 2.027 & 9 & 250 & 2.028 & 10 & 2.031 & 8 \\
\hline 2.017 & 4 & $721+$ & & & & \\
\hline 1.9895 & 8 & $302+$ & 1.985 & 2 & 1.989 & 7 \\
\hline 1.9852 & 10 & $441+$ & & & & \\
\hline 1.9615 & 5 & 640 & 1.961 & 5 & 1.965 & 7 \\
\hline 1.9554 & 4 & $022+$ & & & & \\
\hline 1.9438 & 7 & $122+$ & 1.943 & 2 & 1.946 & 2 \\
\hline 1.8814 & 15 & 830 & 1.880 & 30 & 1.883 & 14 \\
\hline 1.8583 & 8 & $322+$ & 1.855 & 5 & 1.853 & 3 \\
\hline 1.8508 & 7 & $731+$ & & & & \\
\hline
\end{tabular}

Table 17: (continued). Calculated pattern for UTes (left) and observed, 36-1291 (middle), Boehme et al. (right). 


\begin{tabular}{|c|c|c|c|c|c|c|}
\hline d & $I^{r e l}$ & $\begin{array}{c}\text { Calculated } \\
\text { hik } \ell\end{array}$ & $\begin{array}{c}\text { 36- } 1291 \\
\text { d }\end{array}$ & $I^{r e l}$ & $\begin{array}{c}\text { Boehme el al. } \\
\text { d }\end{array}$ & $I^{r e l}$ \\
\hline 1.8182 & 9 & 502 & 1.817 & 2 & 1.821 & 2 \\
\hline 1.8003 & 12 & 901 & 1.709 & 10 & 1.801 & 8 \\
\hline 1.7937 & 9 & $132+$ & & & & \\
\hline 1.7817 & 10 & 351 & 1.782 & 5 & 1.786 & 6 \\
\hline 1.7740 & 7 & 911 & & & & \\
\hline 1.7655 & 6 & 1010 & 1.763 & 10 & 1.767 & 6 \\
\hline 1.7345 & 8 & 060 & 1.736 & 20 & 1.738 & 9 \\
\hline 1.7258 & 7 & $332+$ & & & & \\
\hline 1.7184 & 5 & $831+$ & & & & \\
\hline 1.7075 & 3 & 650 & 1.708 & 10 & 1.710 & 5 \\
\hline 1.7029 & 2 & 260 & & & & \\
\hline 1.6973 & 1 & 840 & & & & \\
\hline 1.6555 & 3 & 551 & & & 1.659 & 1 \\
\hline 1.6358 & 1 & 622 & & & 1.638 & 12 \\
\hline 1.6287 & 2 & 1011 & & & & \\
\hline 1.6174 & 1 & 460 & & & & \\
\hline 1.6104 & 5 & $532+$ & & & 1.615 & 4 \\
\hline 1.5979 & 2 & $931+$ & & & & \\
\hline 1.5918 & 1 & $1030+$ & & & & \\
\hline 1.5828 & 10 & 651 & & & 1.585 & 6 \\
\hline 1.5804 & 9 & $342+$ & & & & \\
\hline 1.5720 & 2 & 1021 & & & 1.575 & 2 \\
\hline
\end{tabular}

Table 17: (continued). Calculated pattern for $\mathrm{UTe}_{5}$ (left) and observed, 36.1291 (middle), Boehme ot al. (right). 


\begin{tabular}{|c|c|c|c|c|c|c|}
\hline d & $I^{r e l}$ & $\begin{array}{c}\text { Calculated } \\
\text { hk } \ell\end{array}$ & $\begin{array}{c}36-1291 \\
d\end{array}$ & $I^{\text {rel }}$ & $\begin{array}{c}\text { Boehme el al. } \\
\text { d }\end{array}$ & Irel \\
\hline 1.5538 & 6 & $722+$ & & & 1.556 & 2 \\
\hline 1.5493 & 4 & $361+$ & & & & \\
\hline 1.5194 & 2 & 1101 & & & 1.520 & 1 \\
\hline 1.5103 & 5 & $461+$ & & & 1.514 & 4 \\
\hline 1.5035 & 3 & $1111+$ & & & 1.510 & 2 \\
\hline 1.4998 & 2 & $660+$ & & & & \\
\hline 1.4929 & 3 & $1200 t$ & & & 1.494 & 1 \\
\hline 1.4903 & 3 & 542 & & & & \\
\hline 1.4805 & 5 & 941 & & & & \\
\hline 1.4767 & 12 & 152 & & & 1.478 & 7 \\
\hline 1.4738 & 12 & $732+$ & & & 1.476 & 6 \\
\hline 1.4642 & 5 & 561 & & & 1.468 & 4 \\
\hline 1.4585 & 3 & 1121 & & & & \\
\hline 1.4479 & 3 & 902 & & & & \\
\hline 1.4382 & 2 & $352+$ & & & 1.436 & 1 \\
\hline 1.4339 & 2 & 851 & & & & \\
\hline 1.4110 & 1 & 470 & & & 1.415 & $<1$ \\
\hline 1.4074 & 1 & 1201 & & & & \\
\hline 1.4022 & 2 & $071+$ & & & & \\
\hline 1.3949 & 8 & $922+$ & & & 1.397 & 3 \\
\hline 1.3918 & 5 & 1131 & & & & \\
\hline 1.3854 & 1 & 271 & & & & \\
\hline
\end{tabular}

Table 17: (continued). Calculated pattern for $\mathrm{UTe}_{5}$ (left) and observed, 36-1291 (middle), Boelme et al. (right). 


\begin{tabular}{|c|c|c|c|c|c|c|}
\hline$d$ & $\mathrm{I}^{\text {rel }}$ & $\begin{array}{c}\text { Calculated } \\
h k \imath^{?}\end{array}$ & $\begin{array}{c}\text { 36-1291 } \\
\mathrm{d}\end{array}$ & $I^{r e l}$ & $\begin{array}{c}\text { Boehme el al. } \\
\text { d }\end{array}$ & $I^{r e l}$ \\
\hline 1.3801 & 2 & $742+$ & & & & \\
\hline 1.3713 & 2 & $1230+$ & & & 1.371 & 1 \\
\hline 1.3651 & 4 & 371 & & & 1.368 & 2 \\
\hline 1.3616 & 4 & 951 & & & & \\
\hline 1.3578 & 8 & $1050+$ & & & 1.359 & 7 \\
\hline 1.3540 & 5 & 123 & & & & \\
\hline 1.3426 & 6 & $223+$ & & & 1.345 & 1 \\
\hline 1.3382 & 4 & 471 & & & 1.339 & 1 \\
\hline 1.3362 & 4 & $932+$ & & & 1.334 & 1 \\
\hline 1.3309 & 2 & 670 & & & & \\
\hline 1.3241 & 1 & 323 & & & & \\
\hline 1.3121 & 3 & 1141 & & & 1.313 & 2 \\
\hline 1.3074 & 3 & $362+$ & & & & \\
\hline 1.3042 & 8 & $1231+$ & & & 1.306 & 12 \\
\hline 1.3009 & 5 & $080+$ & & & 1.304 & 3 \\
\hline 1.2949 & 1 & 1240 & & & & \\
\hline 1.2925 & 2 & 1051 & & & & \\
\hline 1.2900 & 2 & 233 & & & & \\
\hline 1.2874 & 2 & 280 & & & & \\
\hline 1.2837 & 1 & 462 & & & & \\
\hline 1.2796 & 1 & 1400 & & & & \\
\hline 1.2736 & 3 & 333 & & & & \\
\hline
\end{tabular}

Table 17: (continued). Calculated pattern for $\mathrm{UTe}_{5}$ (left) and observed, 36-1291 (middle), Boelime et al. (right). 


\begin{tabular}{|c|c|c|c|c|c|c|}
\hline d & $I^{r e l}$ & $\begin{array}{c}\text { Calculated } \\
\text { hk } \ell\end{array}$ & $\begin{array}{c}36-1291 \\
\text { d }\end{array}$ & $I^{r e l}$ & $\begin{array}{c}\text { Boeh me el al. } \\
\text { d }\end{array}$ & $I^{r e l}$ \\
\hline 1.2704 & 4 & $1321+$ & & & 1.271 & 1 \\
\hline 1.2652 & 5 & 942 & & & 1.267 & 2 \\
\hline 1.2631 & 4 & 613 & & & & \\
\hline 1.2550 & 3 & 562 & & & & \\
\hline 1.2516 & 4 & $433+$ & & & 1.252 & 1 \\
\hline 1.2491 & 4 & $961+$ & & & & \\
\hline 1.2461 & 2 & 1060 & & & & \\
\hline 1.2426 & 1 & 1420 & & & 1.243 & 1 \\
\hline 1.2386 & 2 & $870+$ & & & & \\
\hline 1.2313 & 3 & $281+$ & & & 1.216 & 1 \\
\hline
\end{tabular}

Table 17: (continued). Calculated pattern for $\mathrm{UTe}_{5}$ (left) and observed, 36-1291 (middle), Boehme et al. (right). 


\section{Summary and Conclusions}

The sta us of the powder diffraction patterns and structural models for the phases in the uranium tellurium system is:

1. UTe - The cubic structural model is correct. An experimental pattern for this phase is needed. In the interim the calculated $15-865$ should be used.

2. $\mathrm{U}_{3} \mathrm{Te}_{4}-\mathrm{The}$ cubic structural model is correct. The calculated pattern represents a considerable improvement over the early Debye-Scherrer pattern with visual intensities and should be adopted as the standard until a modern experimental pattern becomes available. Pattern 12 610 is poor but should be retained until a better one becomes available.

3. $\mathrm{U}_{3} \mathrm{Te}_{4}-$ The orthorhombic structure of this defect phase needs to be refined in order to establish the locations of the vacancies. No experimental pattern lias ever been published.

4. $\mathrm{U}_{2} \mathrm{Te}_{3}$ (Cubic) - The cubic form has never had a powiler pattern published. The reasonable assumptions in our calculated model lead us to recommond the adoption of this pattern as a PDF reference until a proper experiment.., pattern becomes available.

5. $\mathrm{U}_{2} \mathrm{Te}_{3}$ (Orthorhombic) - The orthorhombic stibnite structural nodel is in bad need of refinement against a good powder diffraction pattern, which does not pes sently exist. The current PIF patterns contain 
substantial errors. We recommend the use of our calculated pattern as an im rovement over the existing standards; however, this pattern is almost certain to have substantial disagreement with the true powder pattern if one is ever measured. Pattern $34-807$ is quite poor but should be retained pending publication of a better one.

6. $\mathrm{U}_{3} \mathrm{Te}_{5}-$ There is neither a structural model nor a reliable powder diffraction pattern for this phase. A high quality experimental pattern and structure analysis is needed. Patterns 21-1407, 34-766 and 34-896 almost certainly contain substantial errors.

7. $\mathrm{U}_{7} \mathrm{Te}_{12}$ - Only prorly measured Debye-Scherrer data is avaiiable for this phase. The structural model produces a calculated powder pattern in substantial disagreement with the observed. Both a new experimental pattern and structural refinement are needed here. In the mean time 24-1368 should be retained.

8. $\mathrm{UTe}_{1.78}$ (Orthorhombic) - It is not clear that this Orthorhombic defect $\mathrm{UTe}_{2}$ structure existis. If it does the calculated powder pattern produced here sh lld be more representative than the PDF pattern reported as $\mathrm{U}_{4} \mathrm{Te}_{i}(21-1401)$ which we have corrected for some minor errors

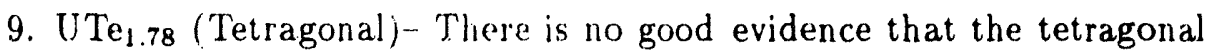
phase exists. 
10. $\mathrm{UTe}_{2}$ (Orthorhombic)- The Orthorhombic $\mathrm{UTe}_{2}$ has a correct crystal structure. Powder pattern 21-1405 contains major errors and should be deleted. Pattern 24-1370 also contains large errors and should be rejected. The calculated pattern is much more representative of this material. The new experimental pattern of Boehme et al. should be used as the reference.

11. UTe $e_{2}$ (Tetragonal)- The tetragonal reports of $\mathrm{UTe}_{2}$ do not warrant including this as a real phase.

12. $\mathrm{VTe}_{2}$ (Cubic)- The recent report of a cubic $\mathrm{UTe}_{2}$ has substantial problems with the structural model. We recommend that pattern 35-1483 be deleted.

13. $\mathrm{UTe}_{2.5}$ - This is probably the only phase lying between $\mathrm{UTe}_{2}$ and $\mathrm{UTe}_{3}$. There is no structural model to produce a calculated pattern. The published powder pattern (21-1409) contains major errors and should be rejected in favor of the recent pattern by Boehme et al. Patterns 21-1402 and 21-1406 claiming to represe $\mathrm{u}_{4} \mathrm{U}_{3} \mathrm{Te}_{7}$ and $\mathrm{U}_{3} \mathrm{Te}_{8}$ should be deleted in that there is no support that these phases exist.

14. $\alpha \mathrm{UTe}_{3}$ - The proposed crystal structure is correct and the pattern computed here represonts a substantiad improvement over 21-1403 and 27-929. The recent pattern of Boelime et al. should be used to represent this phase. 
15. $\beta \mathrm{UTe}_{3}-$ The recent model of Noel is correct and the calculated pattern reported here is the only one available to represent this phase.

16. $\mathrm{UTe}_{3.4}$ - This phase based on the $\beta \mathrm{UTe}_{3}$ structure clearly exists and the recent pattern of Boehme et al. should replace 23-13u9.

17. $\mathrm{UTe}_{5}$ - The model of Nocl accurately predicts the observed pattern 36-1291 and is therefore correct. The recent pattern of Boehme et al. is most complete and should replace 36-1291.

\section{References}

[1] Bayliss, P. and Nowacki, W., Zeit. Krist. 1353 8-315 (1972).

[2] Boehme, D. R., Nichols, M. C., Matheis, D. P. and Snyder, R. L., in preparation (1989).

[3] Breeze, E. W., Brett, N. II. and White, J., J. Nucl. Mater. 39, 157-165 (1971).

[4] Breeze, E. W. and Brot., N. H., J. Nucl. Mater. 40, 113-115 (1971).

[5] Brostigen, G. and Kjekshus, Acta Chem Scand 23, 2187-2188(1969).

[6] Burlet, P., Rossat-Mignod, J., Suski, W., Janus, B., Solid State Comm. $43[7], 587-589$ (1982).

[7] Carter, F. L., J Solid State Chem., 5, 300 (1972). 
[8] Colani, C. R., Acad. Sci. Paris, 137, 383 (1903).

[9] Ellert, G. V., Sevast'yanov, V. G, and Slovyanskikh, V. K., Russian J. Inorg. Chem. 20(1), 120-124 (1975).

[10] Ferro, Von Riccardo, Z. Anorg Chem 275, 320-326(1954).

[11] Furuseth, S., Brattas, L. and Kjekshus, A., Acta Chem Scand 29, 623$631(1975)$.

[12] Grønvold, F., Haraldsen, II., Thurmann,-Moe, T. and Tufte, T., Tech Report to European A tomic Encrgy Agency under contract AF61(052)178 ASTIA No. AD28667 (1962).

[13] Grønvold, F., Drowart, J. and Westrum, E. F., International Atomic Energy Agency, F. L. Oetting, Executive Editor, Vienna, (1984).

[14] Klein-Haneveld, A. J. and Jellinek, F., J. Inorg. Nucl. Chem. 26, 1127 (1964).

[15] Klein-Haneveld, A. J. and Jellinek, F., J. Less-Common Metals 18, 123-129(1969).

[16] Klein-Hane eld, A. J. and Jellinck, F., J. Less-Common Metals 21, 45-49 (1970).

[17] Matson, L. K., Moody, J. W. and Himes, R. C., J. Inorg. Nucl. Chem. $25,795-800(1963)$. 
[18] Meisel, K, 7 A florg. Chem. 240,300(1939).

[19] Himes, V. L. and Mighell, A. D., "NBS*LATTICE: A Program to Analyze Lattice Relationships", NBS Technical Note 1214 (1985).

[20] Noel, H., Mater. Res. Bull. 19, 1171-1175 (1984).

[21] Noel, H. Inorganica Chimica Acta 109, 205-207 (1985).

[22] Noel, H. and Levet, J. C., Journal of Solid State Chemistry, 79, 28-33 (1989).

[23] Pletyushkin, V. A., Chechernikov, V. I, Slovyanskikh, V. K., Vestn. Mosk. Univ., Ser 3, Fiz. Astron. 12, 605 (1971).

[24] Pfoertsch, D. and Ruud, C., Grant-in-aid report to JCPDS (1984) as reported on card 35-1483.

[25] Pfoertsch, D., personal communication (1989).

[26] Smith, D. K., Nichols, M. C. and Zolensky, M. E., "PoWD10. A FORTRAN IV program for calculating X-ray powder diffraction patterns version 10", The Pennsylvania State University, University Park (10n2).

[27] Slovyanskikh, V. K., Yarembash, E. I., Ellert, G. V. and Eliseev, A. A., Izv. Akad. Nauk SSSR, Neorg mater. 4, 624-626 (1963).

[28] Slovyanskikh, V. K., Rozanov, I. A. and Gracheva, N. V., Zhur. Neo. Khimii, 22, 1645-1650 (1977). 
[29] Salem,. A. Ben, Meerschaut, A. and Rouxel, J., C. R. Acad. Sc. Paris, 299[10] 617-619 (1981).

[30] J. K. Stalick and A. D. Mighell, "Crystal Data", NBS Technical Note 1229 (1986) as published by the International Centre for Diffraction Data-JCPDS distributors, 1601 Park Lane, Swarthmore, PA 19081.

[31] Suski, W. and Reizner-Netter, H., Bull De L'Academie Polonaise Des Sciences, Serie des sciences chimiques, 22701 (1974).

[32] Suski, W., Wojakowski, A., Blaise. A., Salmon, P., Fournier, J. M. and Mydlarz, T., J. Mag. Materiads, 3, 195 (1976).

[33] Suski, W., Bull De L's addemice Polonaise Des Sciences, Serie des sciences chimiques, $24,75(1976)$.

[34] Suski, W. and Janus, B., Bull De L'Academie Polonaise Des Sciences, Serie des sciences chimiques, 28[3], 199 (1980).

[35] Zachariasen, W. H., Acta (ryst., 2, 57 (1949). 

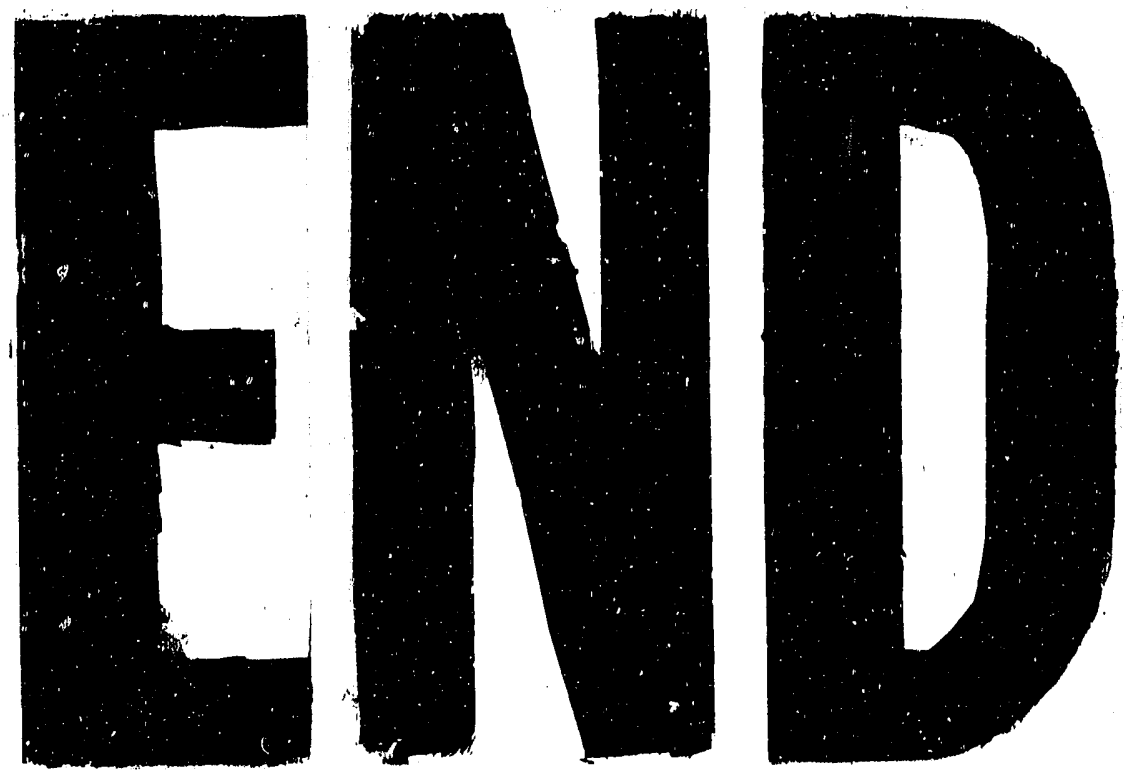

(4)
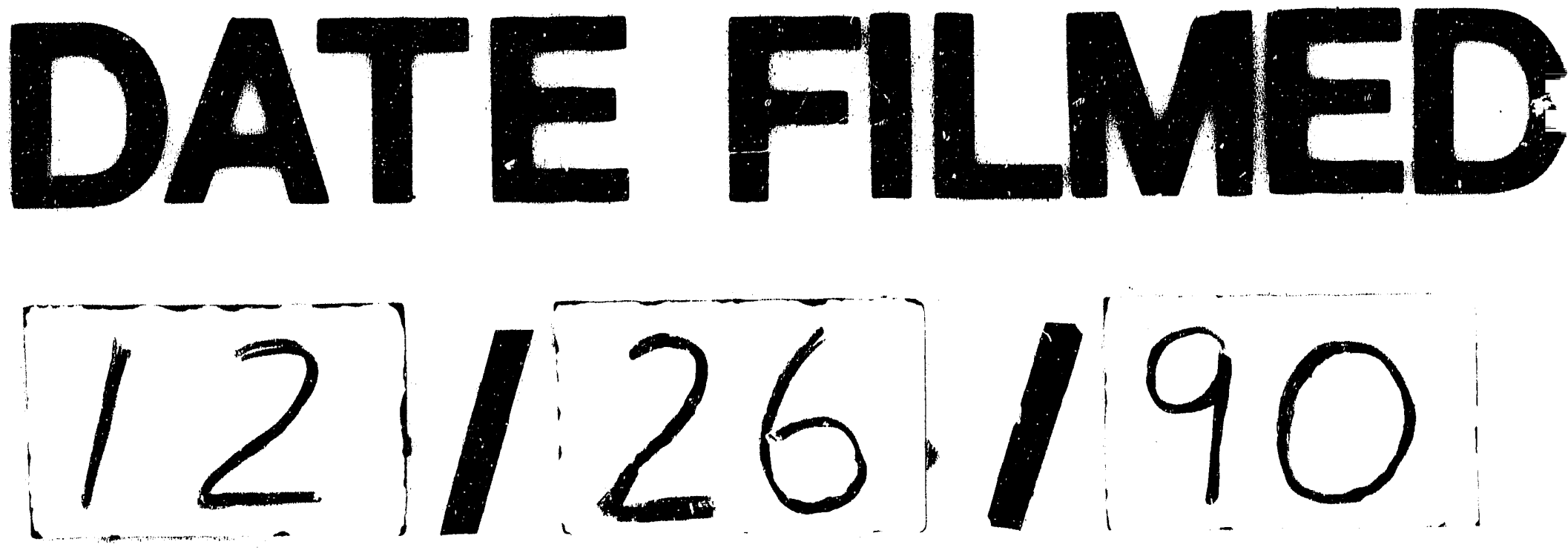
